\title{
Neuropsychiatric Symptom Modeling in Male and Female C57BL/6J Mice after Experimental Traumatic Brain Injury
}

\author{
Laura B. Tucker,, John F. Burke,,2 Amanda H. Fu, ${ }^{1,2}$ and Joseph T. McCabe ${ }^{1,2}$
}

\begin{abstract}
Psychiatric symptoms such as anxiety and depression are frequent and persistent complaints following traumatic brain injury (TBI). Modeling these symptoms in animal models of TBI affords the opportunity to determine mechanisms underlying behavioral pathologies and to test potential therapeutic agents. However, testing these symptoms in animal models of TBI has yielded inconsistent results. The goal of the current study was to employ a battery of tests to measure multiple anxiety- and depressive-like symptoms following TBI in C57BL/6J mice, and to determine if male and female mice are differentially affected by the injury. Following controlled cortical impact (CCI) at a parietal location, neither male nor female mice showed depressive-like symptoms as measured by the Porsolt forced-swim test and sucrose preference test. Conclusions regarding anxiety-like behaviors were dependent upon the assay employed; CCI-induced thigmotaxis in the open field suggested an anxiogenic effect of the injury; however, results from the elevated zero maze, light-dark box, and marble-burying tests indicated that CCI reduced anxiety-like behaviors. Fewer anxiety-like behaviors were also associated with the female sex. Increased levels of activity were also measured in female mice and injured mice in these tests, and conclusions regarding anxiety should be taken with caution when experimental manipulations induce changes in baseline activity. These results underscore the irreconcilability of results from studies attempting to model TBIinduced neuropsychiatric symptoms. Changes in injury models or better attempts to replicate the clinical syndrome may improve the translational applicability of rodent models of TBI-induced anxiety and depression.
\end{abstract}

Keywords: anxiety; depression; mouse; sex differences; TBI

\section{Introduction}

$\mathbf{P}$ SYCHIATRIC SYMPTOMS are among the most common complaints of patients who have survived a traumatic brain injury (TBI). Estimated prevalence rates vary because of population heterogeneity and assessment procedures; however, it is generally agreed that TBI is a risk factor for one or more psychiatric diagnoses, particularly depression and anxiety. ${ }^{1-4}$ These disorders can persist for many years following the injury, ${ }^{4,5}$ and are ultimately associated with a poorer psychosocial outcome. ${ }^{2,6}$ There are currently no United States Food and Drug Administration (FDA)approved agents specifically for the management of TBI-induced depression, although selective serotonergic reuptake inhibitors (SSRIs) are commonly prescribed to help alleviate symptoms. ${ }^{7}$

Animal models of TBI are of immeasurable value in testing potential therapeutic agents; however, ultimately all TBI clinical trials have failed. A recent meta-analysis evaluated 91 drugs, and found that 16 of them improved cognitive and motor impairments in adult male rodents; however, none of the agents tested at that time improved anxiety-like or depressive-like behaviors following TBI. ${ }^{8}$ This failure may reflect the inability to identify the correct pathological mechanisms that need to be targeted to treat these symptoms, or, an inability of current paradigms for measuring depression and anxiety to accurately model the symptoms of clinical patients. Success in simply modeling core features of depression and anxiety following experimental TBI has been very modest, with inconsistent results. ${ }^{9}$

The majority of translational TBI studies have been conducted on male rodents, and it is estimated that in biomedical sciences the neuroscience discipline has the strongest male bias, with male animals outnumbering female animals 5.5 to $1 .{ }^{10}$ In the field of neurotrauma, it has been demonstrated that administration of

\footnotetext{
${ }^{1}$ Pre-Clinical Studies Core, Center for Neuroscience and Regenerative Medicine, Uniformed Service University of the Health Sciences, Bethesda, Maryland.

${ }^{2}$ Department of Anatomy, Physiology, and Genetics, F.E. Hébert School of Medicine, Uniformed Services University of the Health Sciences, Bethesda, Maryland.
}

(c) Laura B. Tucker, et al. 2016; Published by Mary Ann Liebert, Inc. This Open Access article is distributed under the terms of the Creative Commons Attribution Noncommercial License (http://creativecommons.org/licenses/by-nc/4.0/) which permits any noncommercial use, distribution, and reproduction in any medium, provided the original author(s) and the source are credited. 
progesterone improves functional recovery in male rats, ${ }^{11,12}$ and that female rodents may outperform male rodents on tests of motor coordination and cognitive function. ${ }^{11,13-15}$ However, sex differences in these behavioral domains, if present, are often transient and modest. ${ }^{13-16}$ In addition, estrous cycle stage at the time of injury has been shown to have little effect on post-injury performance of female rodents on motor and cognitive tasks. ${ }^{13,17}$

To date, there are no studies comparing performance of male and female rodents on neuropsychiatric tests following TBI. In general, women are more than twice as likely to be diagnosed with a mood or anxiety disorder, ${ }^{18}$ and despite laboratory data showing that female hormones confer a neuroprotective effect, ${ }^{19-22}$ there is clinical evidence that women are more susceptible to developing psychiatric disorders following mild TBI. ${ }^{4,23,24}$ The goal of this study is to employ multiple tests to assess anxiety and depression, which are very common post-TBI symptoms, in a mouse model. We hope that by having data from multiple assays, we can draw more general conclusions regarding these symptoms in experimental models, and that we can provide data describing sex differences in these symptoms following TBI, as female subjects are now required in all pre-clinical research. ${ }^{25}$

Our findings indicate that conclusions regarding anxiety-like symptoms in rodents following TBI are dependent on the assay employed, with findings from the open field (OF) suggesting a TBIinduced increase in anxiety in all mice; however, results from the elevated zero maze (EZM) and light-dark box (LDB) that indicate brain-injured mice and female mice were less anxious. General activity levels were also greater in female mice and in injured mice, and this increase in arousal may complicate findings from anxiety tests. Furthermore, anhedonia and behavioral despair (measures of depressive-like behaviors) were unaffected by brain injury or sex. These findings are discussed in the context of previous conflicting literature describing emotional symptoms in TBI translational studies, and the difficulties of accurately modeling complex diagnoses in clinical populations are considered.

\section{Methods}

\section{Animals and housing}

Male and cycling female C57BL/6J mice 9-10 weeks old at the time of sham or injury procedures were obtained from Jackson Laboratories (Bar Harbor, ME) and allowed to acclimate to housing facilities for 10-14 days prior to baseline behavioral testing. Males (weighing 21.8-29.8 g) and females (weighing 16.6-21.7 g) were group housed (five in each cage) in separate cages with standard enrichment (cotton nestlets and huts or igloos) until post-injury day (PID) 10, when they were separated into individual cages (also with standard enrichment) for the duration of the study. Individual housing was "semisocial" as the mice could view other mice in the adjacent cages. Food (Harlan Teklad Global Diets 2018, 18\% protein) and water were available ad libitum, and the room was on a standard 12:12 h light:dark cycle. All experimental procedures were performed by female investigators. ${ }^{26}$ Facilities are accredited by the Association for the Advancement and Accreditation of Laboratory Animal Care, and all procedures described were approved by the institutional animal care and use committee at the Uniformed Services University of the Health Sciences (Bethesda, MD).

\section{Controlled cortical impact (CCl) and sham procedures}

The number of animals in each group was determined prior to the beginning of the study. Mice were randomly assigned to receive sham procedures (male, $n=17$; female, $n=17$ ), mild CCI (male, $n=16$; female, $n=16$ ), or severe CCI (male, $n=17$; female, $n=17$ ) as previously described. ${ }^{16,27}$ Briefly, mice were anesthetized in a clear induction chamber with $3 \%$ isoflurane in $100 \%$ oxygen until corneal and pedal reflexes were absent. Anesthesia (1.5\% isoflurane) was maintained during procedures via a flow-through nose cone, and body temperature was maintained at $37^{\circ} \mathrm{C}$. Head hair was clipped, and mice were placed in a stereotaxic device with ear bars and an incisor bar (Stoelting, Wood Dale, IL). A high-speed drill was used to perform a $5 \mathrm{~mm}$ craniectomy over the left parietal cortex. CCI was delivered by the electromagnetically controlled Impact One device (Leica Microsystems, Buffalo Grove, IL). The tip of the impactor ( $3 \mathrm{~mm}$ diameter) was centered over the impact site ( $2.5 \mathrm{~mm}$ posterior to bregma and $1.5 \mathrm{~mm}$ left of midline) at a 15 degree angle relative to the sagittal plane, and a mild $(5.0 \mathrm{~m} / \mathrm{sec}$ velocity, $1.0 \mathrm{~mm}$ depth) or severe $(5.0 \mathrm{~m} / \mathrm{sec}$ velocity, $2.0 \mathrm{~mm}$ depth) cortical contusion was produced. Following the injury, the skin was closed with silk suture and mice were placed into a warm home cage for recovery. Sham-treated animals went through all procedures described except the cortical impact.

\section{Open field (OF)}

The OF apparatus (Stoelting) was $40 \mathrm{~cm} \times 40 \mathrm{~cm}$ with opaque walls and illumination of $\sim 175$ lux. Each apparatus had an overhead camera connected to a computer with Any-Maze tracking software (Stoelting). Mice were individually placed into the center of the apparatus, and the software recorded movements of the animals for a 20 min session. Measures obtained and analyzed included the total distance traveled, and the distance traveled in the software-defined $20 \mathrm{~cm} \times 20 \mathrm{~cm}$ center region of the apparatus (expressed as a percentage of the total distance).

On the day prior to CCI or sham procedures, each mouse was placed in an OF environment for 20 min for acclimation and baseline measurements. Subsequent sessions were conducted in the mornings on days 1,10 , and 20 following injury or sham procedures.

\section{Light dark box (LDB)}

On the mornings of days 2 and 21 following CCI or sham treatments, mice were tested in an LDB (Stoelting) for assessment of anxiety. The LDB consisted of a "light" chamber $(40 \mathrm{~cm} \times 20.5 \mathrm{~cm})$ and a "dark" chamber $(24 \mathrm{~cm} \times 19 \mathrm{~cm})$, separated by a "door" $(7 \mathrm{~cm} \times 6.6 \mathrm{~cm})$ in the shared wall. The light chamber had clear walls and was illuminated by overhead lights; light level was $\sim 320$ lux. The dark chamber was enclosed by opaque walls and covered with infrared transparent, dark Plexiglas, and the only light in this chamber was that coming through the door from the light section of the apparatus $(\sim 10$ lux when measured $8 \mathrm{~cm}$ inside the door). Mice were placed in the center of the light chamber, facing away from the door between the two chambers, and allowed to freely explore the apparatus for $10 \mathrm{~min}$. Infrared lights were positioned around the apparatus to allow recording of mouse activity in the dark chamber by an overhead camera. The camera was linked to a computer with Any-Maze software, which reported measures including time spent in the light and dark chambers and the total distance traveled by each animal.

\section{Elevated zero maze (EZM)}

In the afternoons of days 2 and 21 following CCI or sham procedures, anxiety was assessed in the EZM (Stoelting). The EZM is an annular platform divided into four equal quadrants. Two opposite quadrants were "open" but surrounded by an edge $\sim 1 \mathrm{~cm}$ high. The remaining two "closed" quadrants were surrounded by dark, opaque walls $16 \mathrm{~cm}$ high. The platform was elevated $49 \mathrm{~cm}$ above the floor. Overhead fluorescent lamps provided additional illumination; light levels in the open and closed quadrants were $~ 1600$ lux and 200 lux, respectively. Mice were individually placed at a randomly chosen boundary between an open and a closed quadrant, facing the inside of the closed quadrant, and allowed to freely explore the maze for $5 \mathrm{~min}$. 
A ceiling camera tracked the position of each animal, and Any-Maze software calculated the time spent in the open and closed quadrants and the distance traveled during the test session. Videos were later scored by an observer blinded to sex and injury condition of the animals to assess the numbers of U turns, head dips (HDs) (downward movement of the head toward the floor) and stretch-attenuated postures (SAPs) (elongation of the body with the feet remaining in place).

\section{Marble burying test (MBT)}

The MBT was employed to measure anxiety and compulsivelike behaviors 7 days following injury. The test took place in the morning, in a dimly lit room (70 lux). A large, clear Plexiglas box $(45 \mathrm{~cm}$ long $\times 24 \mathrm{~cm}$ wide $\times 22 \mathrm{~cm}$ high) was filled to a depth of $5 \mathrm{~cm}$ with standard wood shavings. Twelve black glass marbles were placed on the surface of the shavings in a rectangular shape, spaced $6.5-9.5 \mathrm{~cm}$ apart. Mice were individually placed in the center of the box; the test session was $30 \mathrm{~min}$. At the end of the session, the numbers of marbles buried to at least a two thirds depth was counted by an investigator blinded to the injury status and sex of the mice.

\section{Sucrose preference test (SPT)}

Following OF testing on PID 10, mice were separated into individual cages. On day 14 following sham or contusion injury, mice were presented with two $20 \mathrm{~mL}$ bottles of $1 \%$ sucrose in their home cages to acclimate them to the sweet taste of sucrose and to the presence of two bottles. The bottles were spaced $\sim 7.5 \mathrm{~cm}$ apart and at an equal height above the bedding of the cage. The amount of sucrose consumed was measured on the mornings of days 15 and 16 following injury by weighing the bottles. On day 16, the SPT began whereby each mouse was given one bottle of $1 \%$ sucrose and one bottle of filtered tap water. The amounts of sucrose and water consumed by each mouse were measured in grams on the mornings of days 17 and 18 following injury. During the middle of the $48 \mathrm{~h}$ test, the positions of the bottles were switched for each animal, to control for any possible side preferences. The sucrose-preference ratio was calculated for the $48 \mathrm{~h}$ test as (consumed sucrose $\times 100) /$ (consumed water + consumed sucrose). Data from two animals (one male sham and one female mild CCI) were excluded because their water bottles were not flowing properly during the test.

\section{Porsolt forced-swim test (FST)}

Learned helplessness/despair was assessed with the Porsolt FST on the morning of day 22 following injury. To ensure equal water temperature for all trials, at least 5 days prior to the test a large water maze tank was filled with tap water and allowed to equilibrate to room temperature $\left(25^{\circ} \mathrm{C}\right)$. The FST chambers (Stoelting) were clear Plexiglas cylinders measuring $42 \mathrm{~cm}$ in height and $19 \mathrm{~cm}$ in diameter. The chambers were filled to a depth of $\sim 25 \mathrm{~cm}$, and mice were individually placed into the cylinders where they remained for $6 \mathrm{~min}$. Following testing, the mice were gently dried with paper towels and placed in a clean cage warmed by a heat lamp. The cylinders were rinsed and fresh water was used for each animal. The sessions were filmed with a standard video camera, and videos were scored offline by an observer blinded to the injury condition and sex of the animals. Videos were imported into Any-Maze software and key presses were used to measure the following behaviors during minutes $2-6$ of the test: immobility (immobility was defined as the animal floating on the surface of the water, only making minimal movements necessary to remain afloat, typically slow paddling of one foot), climbing (forelimbs making vertical movements against the wall of the cylinder), and swimming (horizontal movement in the chamber).

\section{Histological assessment of injury}

Eight mice from each sex and injury group were randomly chosen for lesion volume analysis. Harvesting of tissue and histological analysis of the lesion site was performed as previously described. ${ }^{16}$ Briefly, on day 23 following CCI or sham procedures, all mice were deeply anesthetized and transcardially perfused with $4 \%$ paraformaldehyde (PFA). Brains were removed and post-fixed in PFA for $24 \mathrm{~h}$, at which time they were cryoprotected in $20 \%$ sucrose for $\sim 48 \mathrm{~h}$. Brains were blocked identically, frozen in dried ice powder, and stored at $-80^{\circ} \mathrm{C}$ until they were serially cut into $30 \mu \mathrm{m}$ sections. ImageJ software (National Institutes of Health $[\mathrm{NIH}]$, Bethesda, MD $)^{28}$ was employed to measure the area of serial sections at $540 \mu \mathrm{m}$ intervals. The lesion area for each section was determined by subtracting the area of the hemisphere ipsilateral to the injury site from the area of the hemisphere contralateral to the contusion. The areas for all sections from a mouse were summed, and multiplied by $540 \mu \mathrm{m}$ for the lesion volume estimate.

\section{Statistical analysis}

Statistical analyses were performed using SPSS software (version 21; IBM SPSS Statistics, Armonk, NY). Variables that were measured at multiple points in time were analyzed with a mixeddesign three way analysis of variance (ANOVA) with one repeated measure (day) and two fixed factors (sex and injury status). Wilks' lambda F-statistics resulting from multivariate analyses with measures from each test day as dependent variables are reported. Where significant sex by injury interactions were found, univariate analyses were performed for each sex with injury status as a fixed factor, and Bonferroni-adjusted $t$ test values were used to determine differences among injury groups. The adjusted $t$ test values were also used to determine differences among injury groups on individual testing days following univariate analyses when day by injury interactions resulted from the mixed-design three way ANOVA. With the exception of the number of HDs in the EZM on day 21 and the total distance traveled in the EZM on day 21, all variables passed the homogeneity of variance test as assessed by Levene's test of equality of variances. After a square root transformation, the number of HDs passed Levene's test, and a two way ANOVA was performed on these values. The homogeneity of variance assumption remained violated for the EZM total distance traveled (day 21) data despite multiple tranformations; a KruskalWallis test on the six sex/injury groups was performed on those data, and followed by a stepwise step-down follow-up test. Effect sizes (Cohen's $d$ ) for all main effects of sex were calculated as $\left|\frac{\mu_{\text {female }}-\mu_{\text {male }}}{s_{\text {pooled }}}\right|$, where $\mathrm{s}_{\text {pooled }}=\sqrt{\frac{s_{\text {Female }}^{2}+s_{\text {Male }}^{2}}{2}}$. Cohen's $d$ was also calculated for all main effects of injury; absolute values of the differences between the means of the injury groups were divided by the pooled standard deviations of the relevant injury groups.

Finally, variability in the behavioral data was compared between the sex and injury groups. Coefficients of variation (CVs) were calculated for each treatment group for each behavioral variable on which an ANOVA was performed; repeated measures such as distance traveled in the OF were averaged across days to yield a single CV for each treatment group for each of those variables. A two way ANOVA (sex $\times$ injury) was performed to compare the mean CVs for each treatment group. Additionally, Levene's test for equality of variances was employed to compare the distributions of CVs for each group. ${ }^{29,30}$ The median CV for each group was determined, and a two way ANOVA was performed on the absolute values of the differences between the median $\mathrm{CV}$ and the CVs for each behavioral measure.

Results were considered significant when the $p$ value was $\leq 0.05$, and the data in all figures represent the means \pm standard error of the means. 


\section{Results}

\section{Extent of injury}

Representative brain sections from each sex and injury group are shown in Figure 1A. The severe level of CCI resulted in substantial loss to the ipsilateral cortex, as well as notable damage to the underlying hippocampus. The impact of mild CCI was much less obvious; very little gross damage to the cortex could be observed.

There was no main effect of $\operatorname{sex}\left(F_{1,42}=1.594, p=0.2138\right)$ or interaction between sex and injury $\left(F_{2,42}=0.243, p=0.7850\right)$ on the lesion volume (Fig. 1B); however, there was a main effect of injury $\left(F_{2,42}=152.539, p<0.0001\right)$. Bonferroni-adjusted $t$ tests showed that mice with both mild CCI $(p=0.0079)$ and severe CCI $(p<0.0001)$ had greater lesion volumes than mice that had undergone sham procedures.

\section{OF test}

Analysis of the total distance traveled in the OF during the 20 min test sessions showed a significant interaction between

A

Sham

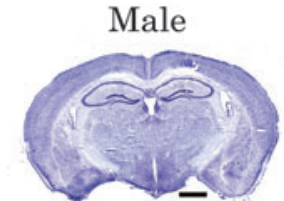

Mild CCI
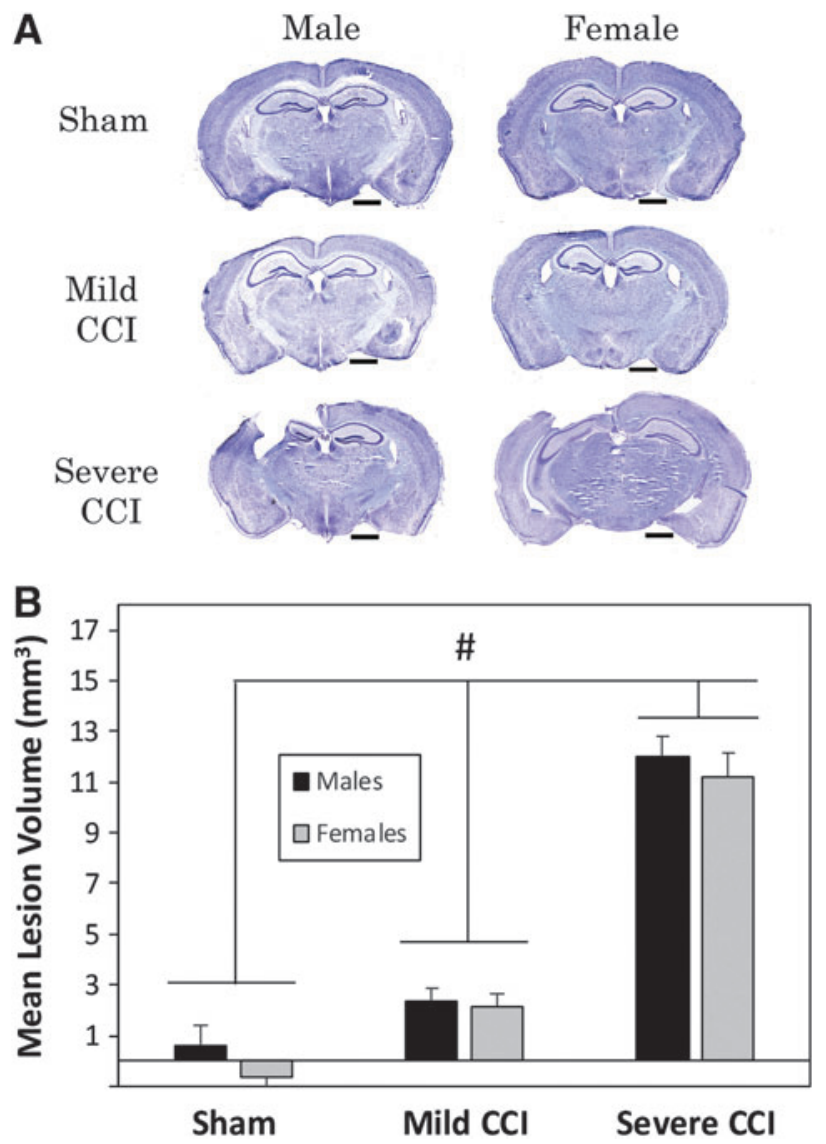

FIG. 1. Controlled cortical impact (CCI)-induced brain injury. Sections shown were stained with cresyl violet and represent the median lesion volume as assessed 23 days following CCI (A). Considerable damage to the ipsilateral cortex and hippocampus resulted from the severe level of CCI (velocity $5 \mathrm{~m} / \mathrm{sec}$, depth $2.0 \mathrm{~mm}$ ). Mild CCI (velocity $5 \mathrm{~m} / \mathrm{sec}$, depth $1.0 \mathrm{~mm}$ ) resulted in little obvious damage. Analysis of lesion volumes $(\mathbf{B})$ showed that mice that sustained both mild and severe CCI had significantly greater lesion volumes than sham-control mice. Horizontal bars in A represent $1 \mathrm{~mm}$. The pound sign (\#) represents a significant effect of the indicated injury group compared with sham controls. testing day and injury status $\left(F_{6,184}=14.678, p<0.0001\right)$, but no interaction between testing day and $\operatorname{sex}\left(F_{3,92}=1.729, p=0.1664\right)$ (Fig 2A and B). There was a significant main effect of sex $\left(F_{1,94}=13.601, p=0.0004\right)$, with female mice ambulating a greater distance in the arena than male mice. Subsequent two way univariate ANOVAs for each testing day revealed that, as expected, there was no effect of injury group on distance traveled during baseline testing $\left(F_{2,94}=0.882, p=0.4172\right)$. However, on all testing days subsequent to injury or sham procedures, injury increased the distance traveled $\left(F_{2,94}=6.053, p=0.0034 ; F_{2,94}=31.339, p<0.0001 ; F_{2,94}=25.972\right.$, $p<0.0001$ for PIDs 1,10 , and 20, respectively) with the severe, but not mild, level of CCI resulting in greater levels of ambulation (Bonferroni $t$ test comparison, $p<0.0036$ ).

Analysis of variance did not reveal any effect of sex on the distance traveled in the center of the OF arena (expressed as a percent of the total distance traveled) $\left(F_{1,94}=0.082, p=0.7753\right)$ or a sex by injury interaction $\left(F_{2,94}=1.824, p=0.1671\right)$; however, there was a significant interaction between day and injury status $\left(F_{6,184}=6.872, p<.0001\right)$ (Fig. $2 \mathrm{C}$ and D). There were no differences between injury groups on the baseline testing prior to injury; however, on all tested PIDs there was an effect of injury status on the distance traveled in the center of the OF arena $\left(F_{2,94}=7.259\right.$, $p=0.0012 ; F_{2,94}=8.761, p=0.0003 ; F_{2,94}=12.198, p<0.0001$ for PIDs 1,10 , and 20, respectively). Bonferroni-adjusted $t$ tests following the univariate ANOVAs for each day showed that only mice with the severe level of CCI had different performance than control animals, with the injured mice traveling less distance in the center of the OF arena $(p<0.0008)$.

\section{$L D B$}

Analysis of the distance traveled in the LDB found significant interactions between injury status and testing day $\left(F_{2,94}=10.310\right.$, $p<0.0001)$ and between sex and testing day $\left(F_{1,94}=5.295\right.$, $p=0.0236$ ). On day 2 after CCI (Fig. 3A), female mice were more active than male mice in the apparatus $\left(F_{1,94}=5.570, p=0.0203\right)$ and injury also affected activity on this day $\left(F_{2,94}=4.058\right.$, $p=0.0204)$. A Bonferroni-adjusted $t$ test showed that mice with mild CCI $(p=0.0337)$ but not sham controls $(p=0.0686)$ ambulated a greater distance than mice with severe CCI. On day 21 (Fig. 3B), the mean distance traveled was equal for all mice regardless of sex or injury condition.

Figures $3 \mathrm{C}$ and $3 \mathrm{D}$ show the amount of time that mice spent in the dark chamber of the LDB on days 2 and 21 following injury, respectively. There were significant interactions between sex and injury status $\left(F_{2,94}=3.445, p=0.0360\right)$, and between injury status and testing day $\left(F_{2,94}=10.142, p=0.0001\right)$. Subsequent univariate analyses for each day showed a significant main effect of injury on day $2\left(F_{2,94}=8.648, p=0.0004\right)$; mice that had sustained severe CCI spent less time in the dark chamber than mice with mild TBI or sham controls (Bonferroni-adjusted $t$ test, $p<0.0140$ ). On day 21, there was an interaction between sex and injury status $\left(F_{2,94}=3.733, p=0.0275\right)$ that resulted from an effect of level of injury in females only $\left(F_{2,47}=3.340, p=0.0440\right)$, with mice that had sustained mild CCI spending less time in the dark chamber than mice with severe CCI (Bonferroni-adjusted $t$ test, $p=0.0476$ ).

Repeated measures ANOVAs (day $\times$ injury) on the time spent in the dark chamber were also performed separately for male and female mice subsequent to the finding of an interaction between sex and injury. In males, there was a main effect of TBI $\left(F_{2,47}=3.615\right.$, $p=0.0346$ ); male mice with mild TBI spent more time in the darkened chamber than male mice with severe CCI (Bonferroni-adjusted 
A
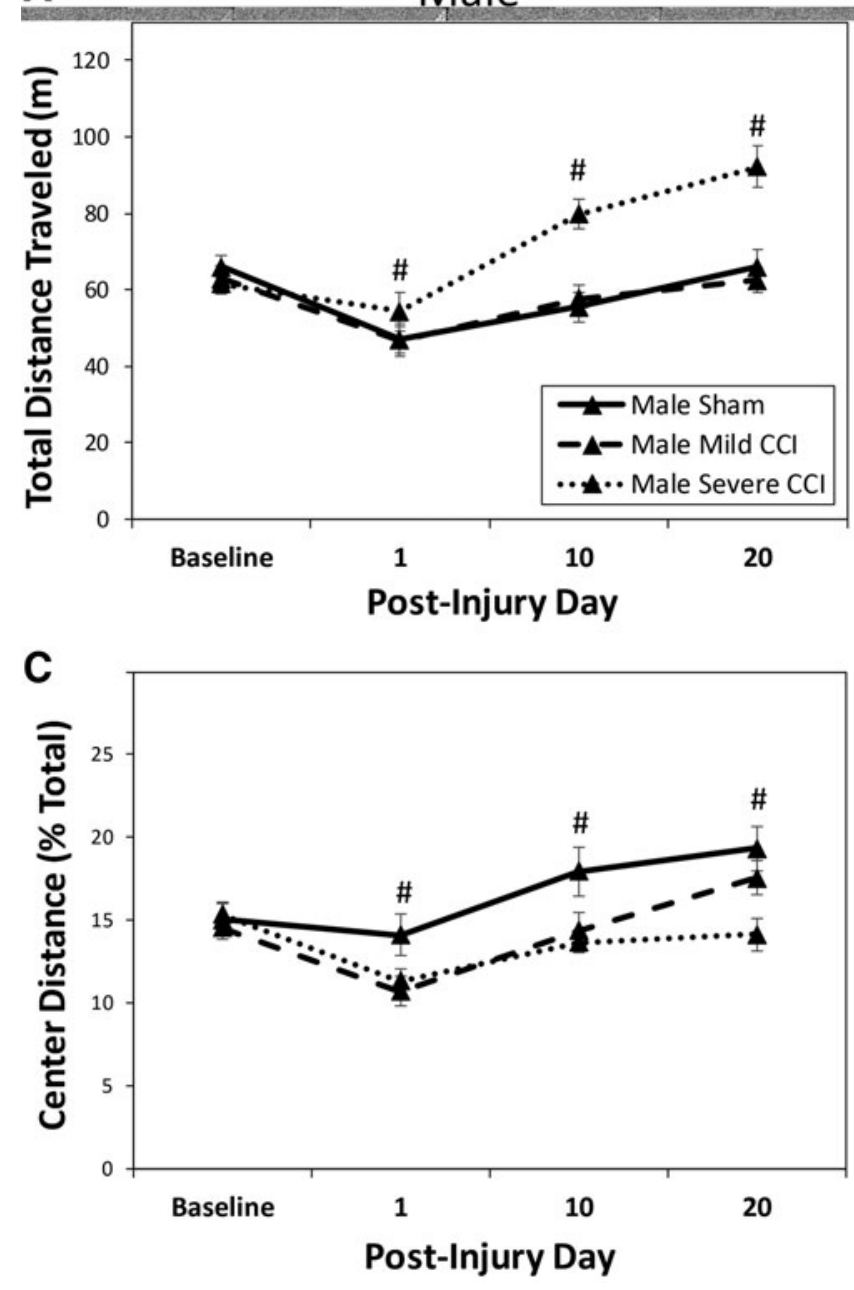

B
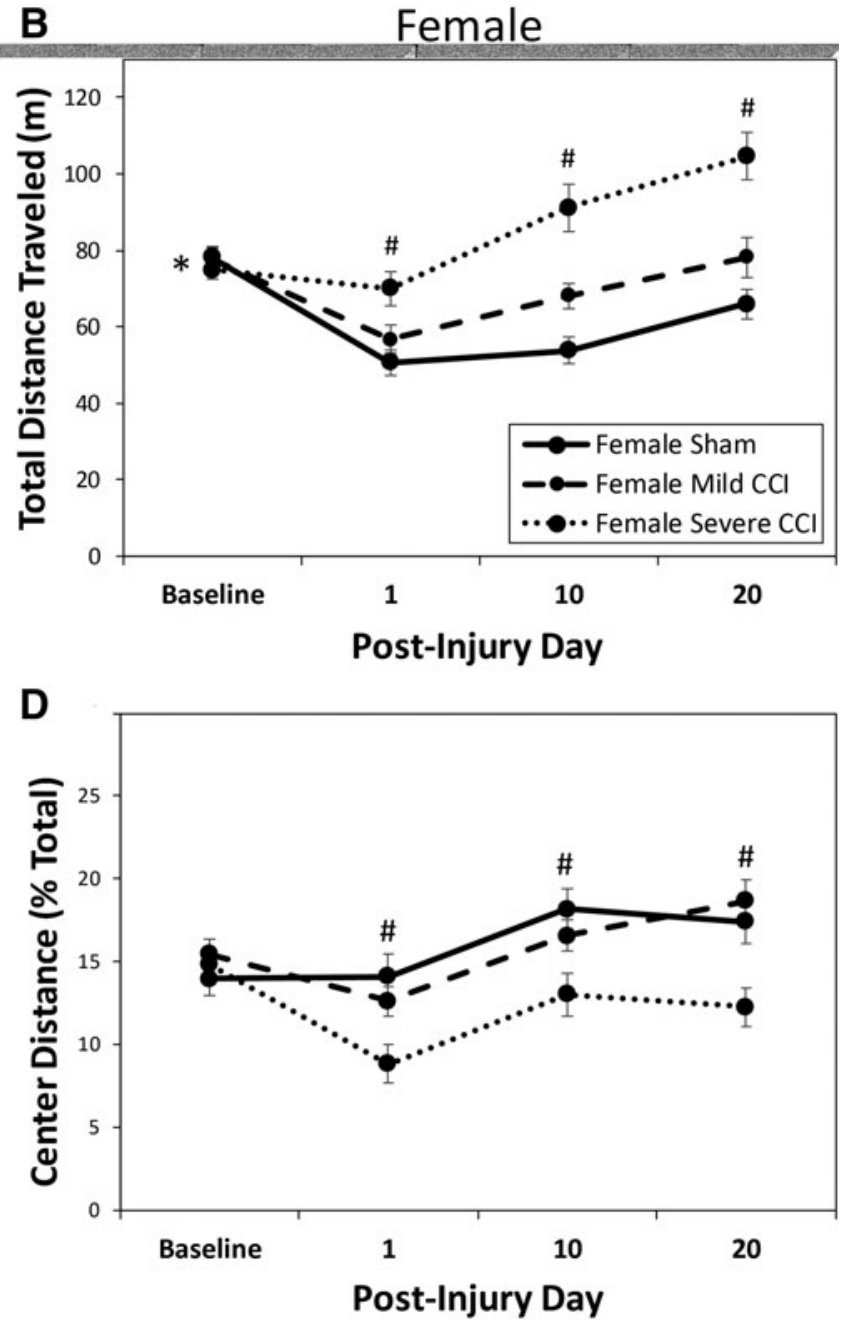

FIG. 2. Open field (OF) behavior following controlled cortical impact (CCI). There was a main effect of sex on activity in the OF, with females (B) ambulating greater distances than males (A). Severe CCI, but not mild CCI, increased the distance traveled in the arena compared with sham controls on all post-injury days ( $\mathbf{A}$ and $\mathbf{B}$, dashed lines). Analysis of center zone activity (C and $\mathbf{D})$, expressed as a function of total activity, suggested that mice with severe, but not mild traumatic brain injury (TBI) were anxious on all post-injury days tested compared with sham controls. The asterisk (*) shown in $\mathbf{B}$ represents the main effect of sex on the distance traveled in the arena (female > male); the pound sign (\#) represents the effect of severe CCI on distance traveled (severe CCI $>$ sham) and center activity (severe CCI < sham).

$t$ test, $p=0.0355)$. There was an injury status by testing day interaction in the female mice $\left(F_{2,47}=10.038, p=0.0002\right)$; the effect of injury on day $2\left(F_{2,47}=4.989, p=0.0108\right)$ was the result of mice with severe CCI spending less time in the dark chamber than mice that had undergone sham procedures (Bonferroni-adjusted $t$ test, $p=0.0095)$, and the effect of injury on day 21 was the result of less time in the dark chamber spent by mice with mild CCI than by mice with severe CCI, as previously described.

\section{$E Z M$}

Figures $4 \mathrm{~A}$ and $\mathrm{B}$ show the main effects of sex and injury status, respectively, on the distance traveled in the EZM. Females ambulated a greater distance in the EZM than males did (main effect of sex, $\left.F_{1,94}=30.555, p<0.0001\right)$ and there was an interaction between injury status and testing day $\left(F_{2,94}=9.745, p=0.0001\right)$. TBI did not affect distance traveled in the maze on the 2 nd day after the injury $\left(F_{2,94}=0.720, p=0.4894\right)$; however, on day 21 following CCI, there was an effect of injury $(\mathrm{H}[5]=30.064, p<0.001)$; step-down followup tests showed that both male and female mice with severe TBI ambulated a greater distance than sham controls $(p<0.05)$.

There was also a significant main effect of sex on the amount of time spent in the dark quadrants of the apparatus (Fig. 4C), with females spending less time in the enclosed sections $\left(F_{1,94}=29.055\right.$, $p<0.0001)$. Additionally, there was a main effect of injury status (Fig. 4D); mice that had sustained severe CCI, but not mild CCI, spent less time in the darkened quadrants of the maze $\left(F_{2,94}=4.867\right.$, $p=0.0097$, Bonferroni-adjusted $t$ test, $p=0.0087, p=0.1323$ for severe and mild CCI vs. sham procedures, respectively).

Figure 5A and B show the mean number of HDs in the EZM on days 2 and 21 following CCI, respectively. On both testing days (2 and 21), female mice made more HDs in the EZM than male mice did $\left(F_{1,94}=8.451, p=0.0046\right)$. There was also a testing day by injury status interaction $\left(F_{2,94}=16.155, p<0.0001\right)$, and univariate ANOVAs for each day showed that on post-injury day 2 , mice with severe TBI made fewer HDs than sham-treated controls 
A

Day 2
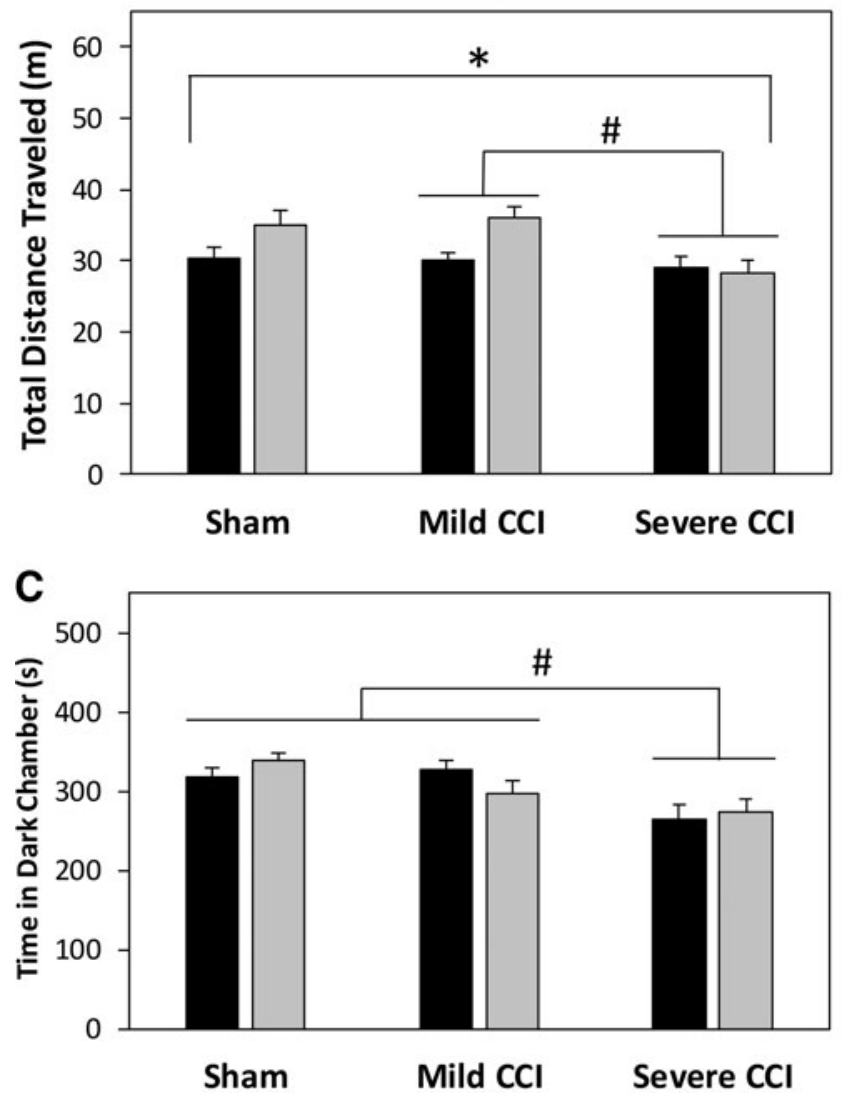

B

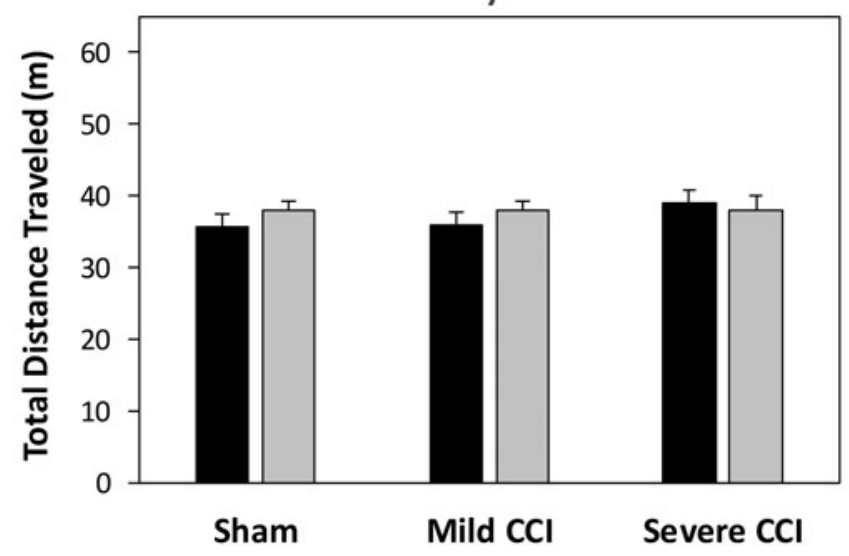

D

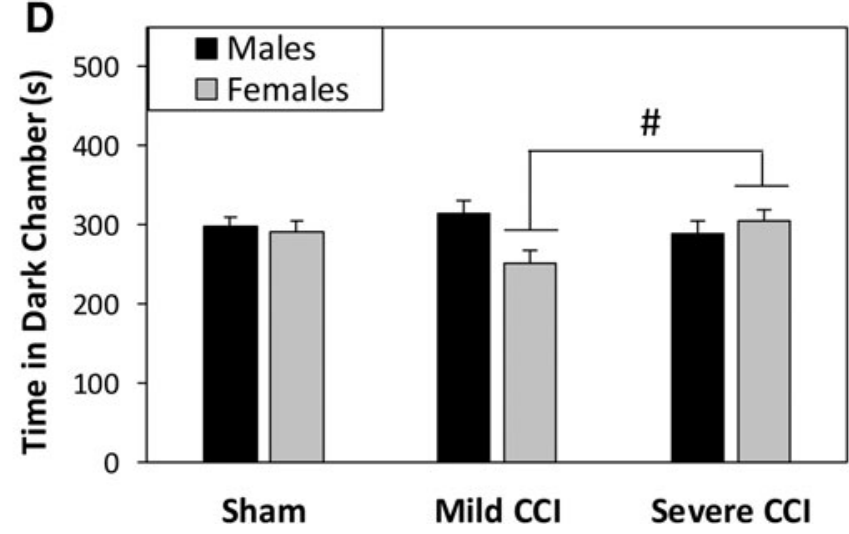

FIG. 3. Anxiety-like behaviors assessed in a light-dark box (LDB). During the first exposure to the LDB (day 2 following injury; A), female mice were overall more active than male mice; however, all mice ambulated equivalent distances on day 21 after injury (B). On day 2 following CCI, mice that had sustained the severe level of injury spent less time in the dark chamber than sham-control mice or mice that had sustained mild CCI (C). On day 21 after injury (D), female mice that had sustained mild CCI spent less time in the darkened chamber than females with the severe injury. The asterisk (*) indicates an effect of sex, and the pound sign (\#) denotes a significant effect of injury.

$\left(F_{2,94}=6.034, p=0.0027\right.$, Bonferroni-adjusted $t$ test, $\left.p=0.0072\right)$; however, on post-injury day 21 , all injured mice made more HDs than uninjured mice did $\left(F_{2,94}=10.537, p \leq 0.0001\right.$, Bonferroniadjusted $t$ test, $p=0.0008, p=0.0002$ for mild CCI and severe CCI compared with sham controls, respectively).

Male and female mice did not differ with respect to the number of U turns made in the EZM on days 2 and 21 following CCI, shown in Figure 5C and D, respectively. The effect of injury on the number of $\mathrm{U}$ turns made by the mice in the apparatus was dependent on testing day $\left(F_{2,94}=8.275, p=0.0005\right)$. On post-injury day 2 only, injury reduced the number of $U$ turns in the EZM $\left(F_{2,94}=5.727\right.$, $p=0.0045)$, and both levels of injury effected this change (Bonferroni-adjusted $t$ test, $p=0.0081, p=0.0225$ for mild CCI and severe CCI compared with sham controls, respectively).

The number of stretch attenuated postures (SAPs) was not affected by injury $\left(F_{2,94}=0.151, p=0.8597\right)$, sex $\left(F_{1,94}=0.055\right.$, $p=0.8147)$, or an interaction between the two factors $\left(F_{2,94}=0.563, p=0.5712\right)$ (data not shown).

\section{$M B T$}

Figure 6 shows the mean number of marbles buried after $30 \mathrm{~min}$. A two way ANOVA (injury $\times$ sex) revealed a significant injury by sex interaction $\left(F_{2,94}=5.508, p=0.0055\right)$. Separate one way ANOVAs for each sex showed that, in females, injury had a significant effect on the number of marbles buried $\left(F_{2,47}=10.425, p=0.0002\right)$, and a Bonferroni $t$ test comparison showed that both mild CCI $(p=0.0218)$ and severe CCI $(p=0.0001)$ reduced the number of marbles buried. Injury also had an effect on the number of marbles the males buried $\left(F_{2,47}=13.321, p<0.0001\right)$; however, only the male mice with severe CCI had a reduction in the number of buried marbles (Bonferroni-adjusted $t$ test, $p=0.0001$ ).

\section{$S P T$}

There was no interaction between sex and injury $\left(F_{2,92}=1.722\right.$, $p=0.1845)$, nor any main effects of $\operatorname{sex}\left(F_{1,92}=0.406, p=0.5258\right)$ or injury $\left(F_{2,92}=1.163, p=0.3172\right)$ in the preference ratio during the SPT (Fig. 7A).

\section{Porsolt FST}

All mice engaged in the same amount of immobility (Fig. 7B), climbing, and swimming behaviors (data not shown) regardless of sex $\left(F_{1,94}=0.007,0.033,0.221 ; p=0.9358,0.8572,0.6395\right.$ for floating, climbing, and swimming, respectively) or injury status $\left(F_{2,94}=2.462\right.$, $2.766,1.563 ; p=0.0907,0.0680,0.2149$ for immobility, climbing and swimming, respectively), and there was no interaction between those two factors $\left(F_{2,94}=0.616,0.086,0.466 ; p=0.5423,0.9176,0.6288\right.$ for immobility, climbing, and swimming, respectively). 

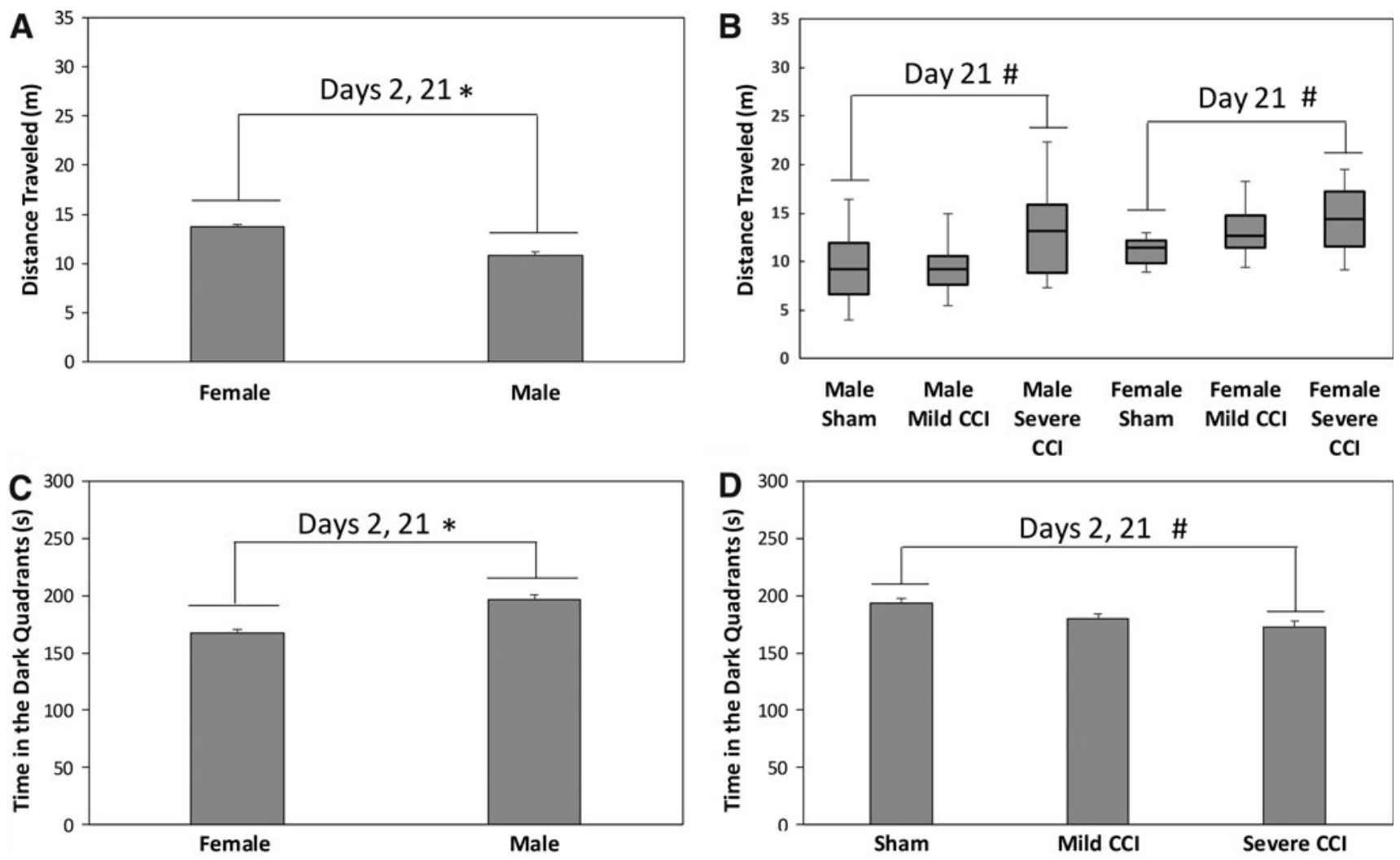

FIG. 4. Activity and anxiety-like behavior in the elevated zero maze. There was a main effect of sex on distance traveled in the elevated zero maze, with female mice ambulating greater distances than male mice (A). Shown in (B) are the results of a Kruskal-Wallis test analyzing the main effects of injury on the distance traveled. The box represents the middle $50 \%$ of the data points, with the line in the box indicating the median; lower and upper boundaries of the boxes are the 25th and 75th percentiles, respectively. The uppermost and lowermost horizontal lines are the range of observed values. Significant differences in distance traveled in the maze were observed in both sexes between sham-control mice and mice that had sustained severe controlled cortical impact (CCI). The effect of sex and injury on the amount of time spent in the dark quadrants are shown in $(\mathbf{C})$ and $(\mathbf{D})$, respectively. Females spent significantly less time in the dark quadrants than male mice $(\mathbf{C})$, and mice with severe CCI spent less time in the dark quadrants than uninjured mice. The asterisks (*) indicate an effect of sex, and the pound sign (\#) denotes a significant effect of injury.

\section{Variability in behavioral data}

The CVs for each reported variable for each sex/injury group are listed in Table 1. A two way ANOVA with sex and injury as fixed factors showed that CVs were not affected by sex $\left(F_{1,78}=0.026\right.$, $p=0.8735)$ or injury $\left(F_{2,78}=1.346, p=0.2662\right)$, and there was no interaction between the two factors $\left(F_{2,78}=0.305, p=0.7381\right)$ (data not shown). Figure 8 shows the range of CVs for each behavioral test. Levene's test for the equality of variances showed that neither sex $\left(F_{1,78}=0.494, p=0.4841\right)$ nor injury status $\left(F_{2,78}=0.063\right.$, $p=0.9394)$ affected the distributions of CVs, and the two factors did not interact $\left(F_{2,78}=0.057, p=0.9445\right)$.

\section{Discussion}

\section{Summary of positive findings}

Tables 2 and 3, respectively, summarize the behavioral measures for which there were effects of sex or injury. As described in our previous study, sex trait differences were largely limited to levels of activity (Table 2), with females ambulating greater distances than males. ${ }^{16}$ Females also spent less time in dark and enclosed regions of the LDB and EZM, and engaged in more HDs in the EZM than male mice, suggesting lower levels of anxiety in the females. The higher levels of activity in female mice have been attributed to activational effects of estrogen. ${ }^{31}$ In terms of injury (Table 3), the results from $\mathrm{OF}$ testing suggest increased anxiety in injured mice; however, the opposite conclusion is reached when testing in the EZM or LDB, which are more anxiety-specific tests. Counting the number of HDs and $U$ turns increased the sensitivity of the EZM, allowing detection of mild CCI effects. Injury also decreased the number of marbles buried in the MBT. Regarding region-specific effects of TBI, hyperactivity following parietal CCI may involve disruption of a complex control system that suppresses activity located on the axis connecting the olfactory bulbs and entorhinal cortex, which would include the parietal cortex and hippocampus. ${ }^{32}$ Finally, the LDB (time in the dark) and MBT were the only tests for which a significant sex by injury interaction was found. Females sustaining mild TBI spent less time in the dark region of the LDB than females with severe TBI, but the opposite was observed in male mice. The MBT was sensitive to both mild and severe CCI in female mice, but only to severe $\mathrm{CCI}$ in the male mice.

\section{Conclusions regarding anxiety-like states in male and female mice after TBI are dependent on behavioral assay}

Male and female brain-injured mice were equally hyperactive in the $\mathrm{OF}$ as measured by the total distance traveled. Although 
A

Day 2

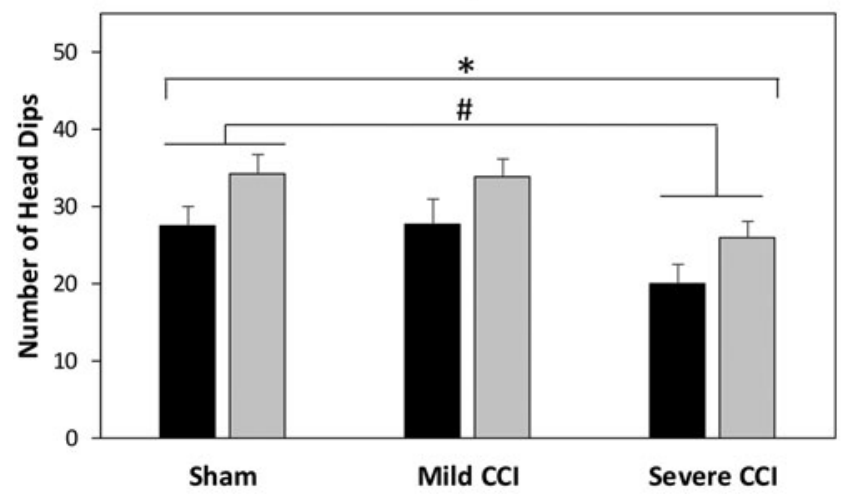

C

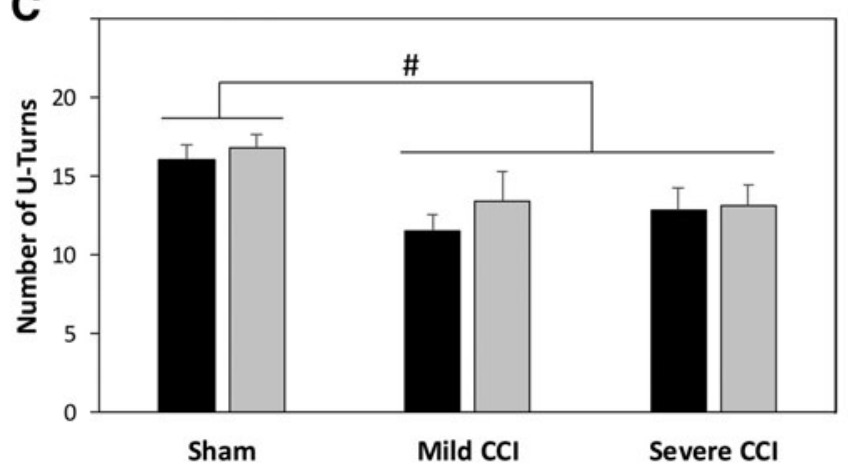

B

Day 21

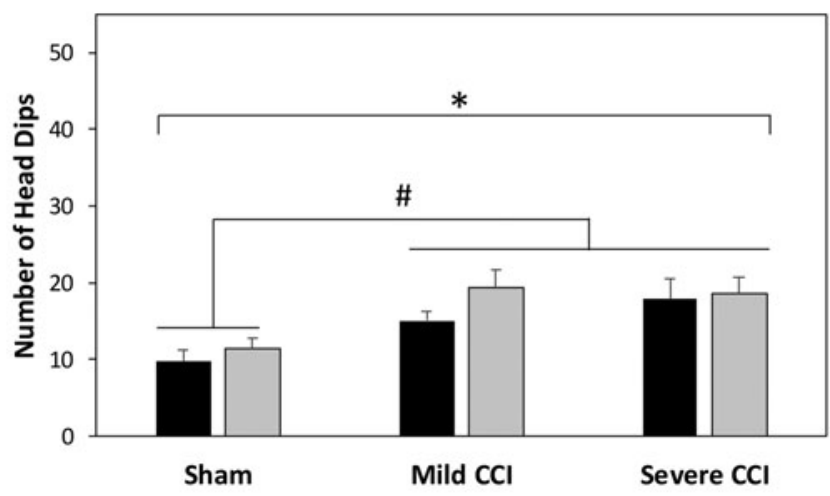

D

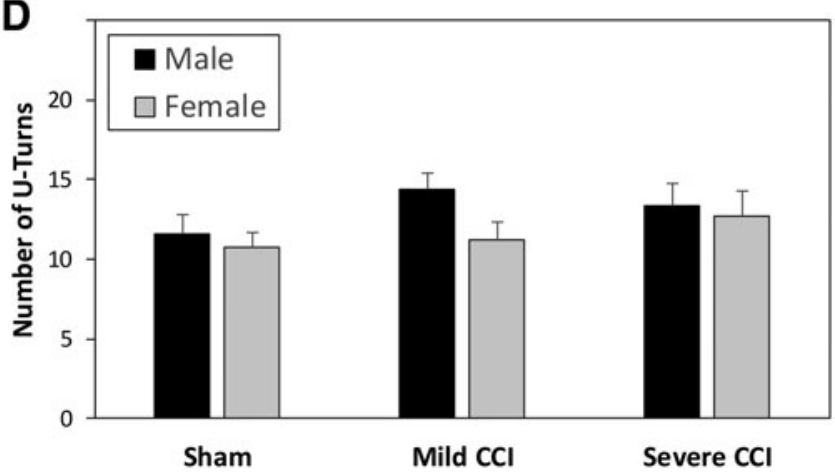

FIG. 5. Head dips and $U$ turns in the elevated zero maze. Female mice made more head dips than male mice on days 2 (A) and 21 (B) following injury. On day 2 following controlled cortical impact (CCI) (A), mice that had sustained severe CCI made fewer head dips than sham controls; however, on day 21 (B), all injured mice made more head dips than sham controls. The number of $U$ turns in the zero maze was reduced in injured mice on day 2 following injury $(\mathbf{C})$, but this measure was equal in all mice on day 21 (D). The asterisks (*) indicate an effect of sex, and the pound sign (\#) denotes a significant effect of injury.

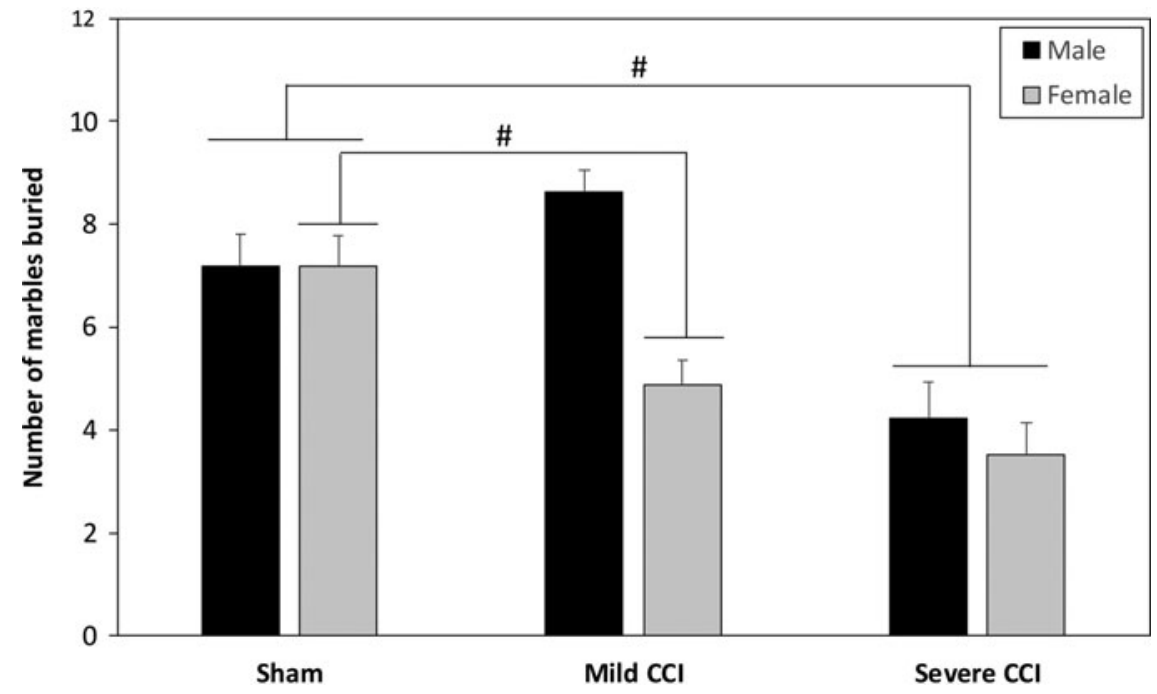

FIG. 6. The number of marbles buried as a result of digging behavior. There was a significant sex by injury interaction for the number of marbles buried in the marble burying test. In females, the mild and severe levels of CCI reduced the number of marbles buried compared with sham controls. In males, only mice that had sustained severe CCI were significantly different from mice that underwent sham procedures. The pound sign (\#) represents a significant effect of injury. 

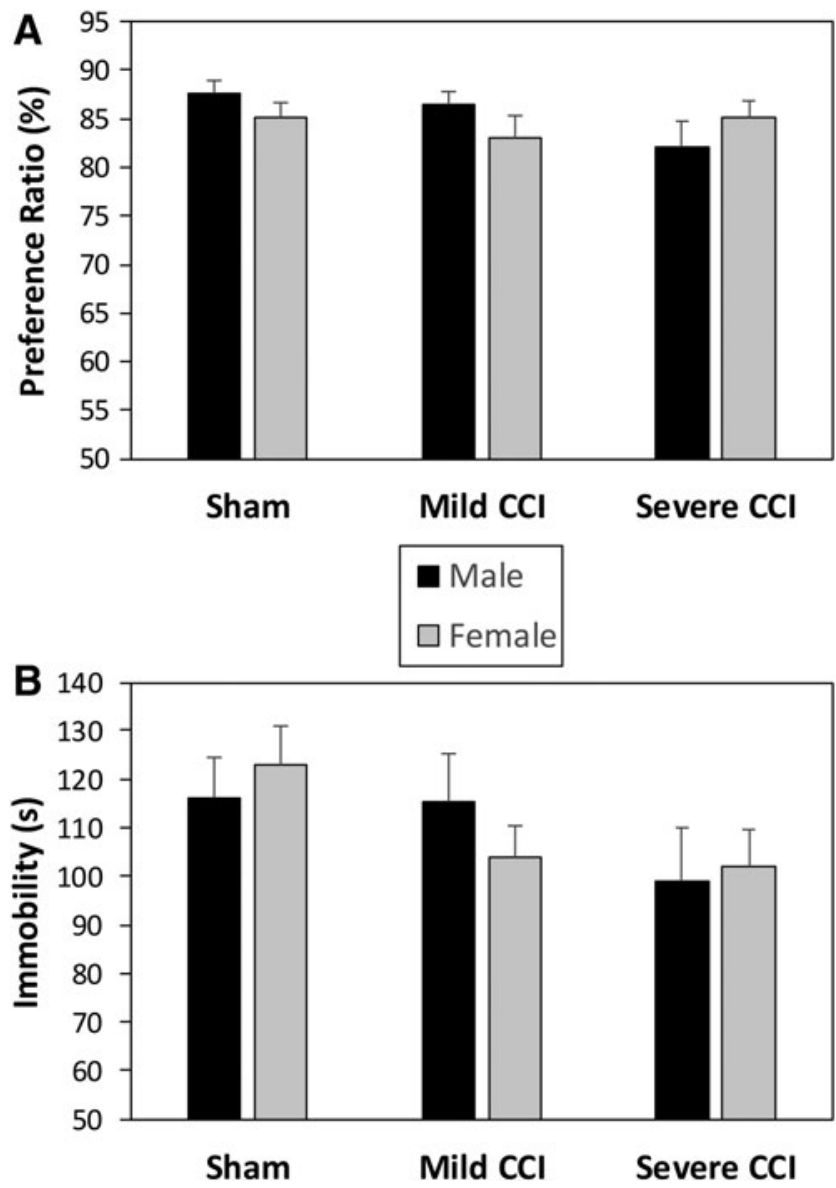

FIG. 7. Anhedonia and behavioral despair following brain injury. There were no effects of injury or sex on anhedonia or behavioral despair as assessed by the sucrose preference test (A) and Porsolt forced-swim test (B), respectively. hyperactivity in an $\mathrm{OF}$ following parietal $\mathrm{CCI}$ is a relatively reliable and robust effect, ${ }^{16,27,33-38}$ it is unclear how the degree of general exploration relates to anxiety-like states in mice. Historically, there is an assumption that high levels of locomotion in the OF represent low "emotionality" or anxiety, ${ }^{39}$ and it was noted very early that most OF studies find higher levels of activity in female mice than in males. ${ }^{40}$ These observations regarding activity would suggest that the male mice and sham-control mice in this experiment were more anxious, as these groups were less active. However, it has been observed that pharmacological agents that are not anxiolytics can increase OF activity in mice, ${ }^{41}$ and it has been suggested that overall locomotor activity is "an unsuitable index of anxiety." 42

As a measurement of anxiety in rodents, activity in the center region of an OF apparatus is better accepted than overall locomotion. Less anxious animals are viewed as more willing to explore the open and brightly lit- "more dangerous" - center of the chamber. ${ }^{43}$ Male and female mice had similar levels of exploration of the OF center region; however, CCI reduced activity in this zone in both sexes, suggesting an anxiogenic effect of brain injury, which confirms previous findings in mice following CCI. ${ }^{16,27,33,34,36}$ Interpretation of OF measures has been criticized for an inability to dissociate exploration, locomotion, and anxiety, ${ }^{44}$ and, as with measures of distance traveled throughout the OF, it has been demonstrated that common anxiolytic agents do not increase the amount of time that $\mathrm{C} 57 \mathrm{BL} / 6 \mathrm{~J}$ mice spend in the center of the arena, indicating that this measure has a low predictive validity for anxiety-like behavior. ${ }^{45,46}$ It has been suggested that positive findings regarding anxiety on the OF test should only be considered preliminary, and should be followed up with more anxiety-specific tests. ${ }^{47}$

This study employed the LDB and EZM as more specific tests of anxiety. These tests take advantage of the rodents' conflict between a desire to explore new environments and a fear of open and brightly lit conditions, and are believed to mimic human generalized anxiety states. ${ }^{48}$ The general conclusion that can be drawn from the data is that, with exception of the OF, brain-injured mice explore the "anxiogenic zones" of these apparatus more than sham controls do. To date, there do not seem to be any studies reporting

Table 1. Mean Coefficients of Variation on each Behavioral Measure for All Treatment Groups*

\begin{tabular}{|c|c|c|c|c|c|c|c|}
\hline & \multicolumn{2}{|c|}{ Sham (\%) } & \multicolumn{2}{|c|}{ Mild CCI (\%) } & \multicolumn{2}{|c|}{ Severe CCI (\%) } & \multirow{2}{*}{$\begin{array}{c}\text { Summary (\%) } \\
\text { Mean } \pm \text { SEM }\end{array}$} \\
\hline & Male & Female & Male & Female & Male & Female & \\
\hline Open field - distance traveled & 28.23 & 20.74 & 19.8 & 21.06 & 20.85 & 22.64 & $22.22 \pm 1.26$ \\
\hline Open field - center distance & 29.18 & 26.51 & 15.94 & 20.64 & 14.59 & 34.73 & $23.60 \pm 3.23$ \\
\hline Light-dark box - distance traveled & 19.06 & 18.93 & 12.89 & 13.36 & 18.28 & 22.44 & $17.49 \pm 1.50$ \\
\hline Light-dark box - time in dark chamber & 13.55 & 13.98 & 13.41 & 23.2 & 20.35 & 17.94 & $17.07 \pm 1.68$ \\
\hline EZM - distance traveled & 27.82 & 9.60 & 22.77 & 16.11 & 27.31 & 23.17 & $21.13 \pm 2.87$ \\
\hline $\mathrm{EZM}$ - time in dark quadrants & 15.11 & 10.05 & 11.49 & 14.18 & 20.96 & 13.54 & $14.22 \pm 1.54$ \\
\hline $\mathrm{EZM}$ - number of $\mathrm{U}$ turns & 23.63 & 18.79 & 26.55 & 33.15 & 38.30 & 41.75 & $30.36 \pm 3.62$ \\
\hline EZM - number of SAPs & 47.09 & 32.64 & 36.04 & 38.97 & 49.04 & 52.47 & $42.71 \pm 3.24$ \\
\hline EZM - number of head dips & 38.46 & 30.87 & 32.99 & 27.78 & 48.34 & 24.16 & $33.77 \pm 3.52$ \\
\hline MBT - number of marbles buried & 36.28 & 34.92 & 19.8 & 40.25 & 70.11 & 71.62 & $45.50 \pm 8.51$ \\
\hline Sucrose preference test - preference ratio & 5.76 & 7.05 & 6.00 & 10.51 & 13.48 & 8.73 & $8.59 \pm 1.22$ \\
\hline Forced swim test - time immobile & 29.29 & 26.16 & 33.89 & 25.02 & 45.69 & 31.36 & $31.90 \pm 3.06$ \\
\hline Forced swim test - time swimming & 41.15 & 37.65 & 33.55 & 20.26 & 54.72 & 45.32 & $38.77 \pm 4.74$ \\
\hline Forced swim test - time climbing & 121.1 & 106.61 & 72.97 & 127.85 & 96.49 & 177.37 & $117.06 \pm 14.43$ \\
\hline Mean & 25.83 & 20.37 & 19.79 & 23.56 & 31.05 & 30.29 & \\
\hline SEM & 3.23 & 2.61 & 2.47 & 2.75 & 4.84 & 4.97 & \\
\hline
\end{tabular}

*No statistical differences in mean variation were observed between levels of injury or sex.

EZM, elevated zero maze; SAP, stretch attenuated posture; MBT, marble burying test; SEM: standard error of the mean. 


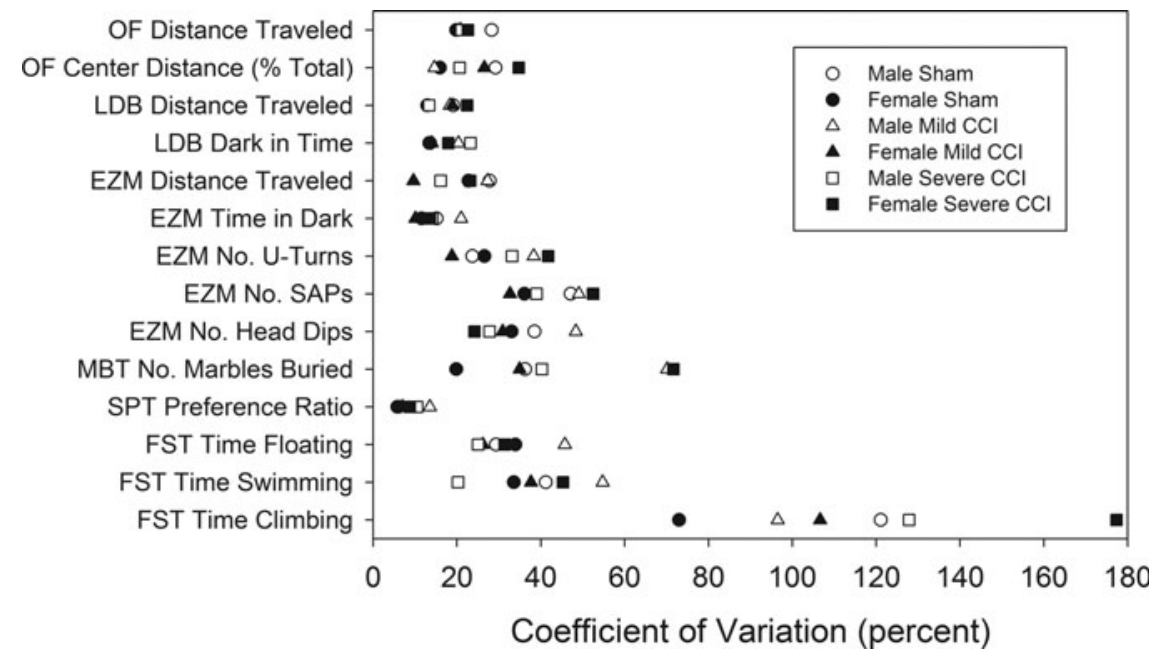

FIG. 8. Variability in behavioral data. For each of the six sex and injury groups, the coefficients of variation are shown for 14 behavioral variables. Levene's test for the equality of variances indicated that there was no effect of sex or injury on the mean coefficient of variation (data not shown) and the distribution of variability was also unaffected by sex and injury. Open and closed symbols represent male and female mice, respectively. Circles, triangles, and squares represent sham, mild controlled cortical impact (CCI), and severe CCI, respectively. OF, open field; LDB, light dark box; EZM, elevated zero maze; MBT, marble burying test; SPT, sucrose preference test; FST, Porsolt forced-swim test.

the effects of TBI on LDB performance in mice, but after frontal $\mathrm{CCI},{ }^{49}$ or a mild blast injury, ${ }^{50,51}$ Sprague-Dawley rats spent less time in the brightened chamber than sham rats, did suggesting heightened levels of anxiety.

The elevated plus maze (EPM) and EZM are similar to the LDB, but have an additional component of height. The EZM has the advantage over the EPM of removing the ambiguity of the center square ${ }^{52}$ Results from the EPM and EZM are comparable, ${ }^{53}$ and although both have been employed in many TBI rodent studies, results are very inconsistent. Many studies report an injury-dependent decrease in the amount of time spent in anxiogenic regions of the apparatus, ${ }^{54-60}$ consistent with what would be expected, given the clinical presentation of anxiety. However, at least as many studies report no effect of TBI on anxiety-like behaviors, ${ }^{61-69}$ or, consistent with this study, that TBI reduces anxiety. ${ }^{70-73}$ Petraglia and colleagues reported that behavior of C57BL/6J mice in the EPM following concussive impacts was dependent upon the time after the injury at which the test was performed: single or multiple concussive injuries resulted in increased anxiety at a 2 week time period following injury, but at 1 and 6 months, mice that had sustained multiple concussions showed decreased anxiety. ${ }^{74}$

It is critical to note that the interpretation of results derived from the EZM, EPM, and LDB have raised at least three concerns. First, Cryan and Holmes emphasized that these tests are unable to dis- sociate impulsivity or novelty-seeking behaviors from a reduction in anxiety states. ${ }^{75}$ In the context of sleep research, it has been noted that sleep deprivation in people is consistently anxiogenic whereas sleep deprivation in rodent models rarely causes an anxiety-like state when assessed with the EPM. Further, it is suggested that when an experimental manipulation (i.e., sleep deprivation) results in a complex phenotype in an animal model, symptoms such as anxiety and impulsivity can be comorbid and render tests such as the EPM and EZM less applicable to the study of human conditions. ${ }^{76}$ And perhaps more importantly in the current context, the tests rely on the rodents' exploration. In this TBI study (Table 3), as well as in many others, levels of activity in all tests of anxiety were significantly affected by the injury. Therefore, activity is a critical factor, and differences among groups in activity levels may confound interpretations regarding anxiety-like states. ${ }^{75,77-81}$

\section{Sex differences in performance on unconditioned anxiety tests}

This is the first study to measure sex differences in anxiety- and depression-like behaviors following experimental TBI. Differences between male and female mice were found in activity levels in the OF, LDB, and EZM, with females moving greater distances in those apparatuses, independent of injury status. Greater activity

Table 2. Summary of Significant Differences Between Male $(N=50)$ and Female $(N=50)$ Mice

\begin{tabular}{llccc}
\hline & Main effect of sex & p value & Power & Effect size (Cohen's d) \\
\hline OF distance traveled & Female > Male & 0.0004 & 0.9545 & 0.4590 \\
LDB Day 2, distance traveled & Female > Male & 0.0203 & 0.6465 & 0.4459 \\
EZM distance traveled & Female > Male & $<0.0001$ & 1.000 & 0.8466 \\
EZM time in dark quadrants & Male > Female & $<0.0001$ & 1.000 & 0.8046 \\
EZM head dips & Female > Male & 0.0046 & 0.8205 & 0.3607 \\
\hline
\end{tabular}

Shown are the behavioral measures in the current experiment for which a significant main effect of sex was found. $P$ values from analyses of variance (ANOVAs), power $(1-\beta)$, and calculated effect sizes (Cohen's $d$ ) are provided. Cohen's $\mathrm{d}=\left|\frac{\mu_{\text {female }}-\mu_{\text {male }}}{s_{\text {pooled }}}\right|$

$\mathrm{OF}$, open field; LDB, light-dark box; EZM, elevated zero maze. 
Table 3. Summary of Significant Main Effects of Injury

\begin{tabular}{|c|c|c|c|c|c|}
\hline \multirow[b]{2}{*}{ Behavioral measure } & \multirow[b]{2}{*}{ Main effect of injury } & \multirow[b]{2}{*}{$\mathrm{p}$ value } & \multirow[b]{2}{*}{ Power } & \multicolumn{2}{|c|}{ Effect size (d or $\mathrm{r})$} \\
\hline & & & & Mild & Severe \\
\hline OF distance traveled, Day 1 & Severe $>$ Sham & 0.0034 & 0.8753 & N/A & 0.7322 \\
\hline OF distance traveled, Day 10 & Severe $>$ Sham & $<0.0001$ & 1.000 & N/A & 1.588 \\
\hline OF distance traveled, Day 20 & Severe $>$ Sham & $<0.0001$ & 1.000 & N/A & 1.523 \\
\hline OF center activity, Day 1 & Sham $>$ Severe & .0012 & 0.9291 & N/A & 0.8633 \\
\hline OF center activity, Day 10 & Sham $>$ Severe & 0.0003 & 0.9664 & N/A & 0.9834 \\
\hline OF center activity, Day 20 & Sham $>$ Severe & $<0.0001$ & 0.9947 & N/A & 1.036 \\
\hline LDB time in dark, Day 2 & Sham $>$ Severe & 0.0004 & 0.9644 & N/A & 0.9591 \\
\hline EZM distance traveled, Day 21, Male & Severe $>$ Sham & $<0.001$ & - & N/A & 0.4074 \\
\hline EZM distance traveled, Day 21, Female & Severe $>$ Sham & $<0.001$ & - & N/A & 0.4349 \\
\hline EZM time in dark quadrants & Sham $>$ Severe & 0.0097 & 0.7908 & N/A & 0.6401 \\
\hline EZM head dips, Day 2 & Sham $>$ Severe & 0.0027 & 0.8889 & N/A & 0.7764 \\
\hline EZM head dips, Day 21 & Severe, Mild $>$ Sham & $<0.0001$ & 0.9868 & 1.014 & 0.9473 \\
\hline EZM U turns, Day 2 & Sham $>$ Mild, Severe & 0.0045 & 0.8557 & 0.7802 & 0.7319 \\
\hline MBT marbles buried, Male & Sham $>$ Severe & $<0.0001$ & 0.9964 & N/A & 1.054 \\
\hline MBT marbles buried, Female & Sham $>$ Mild, Severe & 0.0002 & 0.9832 & 1.027 & 1.448 \\
\hline
\end{tabular}

Shown are the behavioral measures in the current experiment for which a significant difference between injured mice and sham controls was found. $P$ values from analyses of variance (ANOVAs), power $(1-\beta)$ and calculated effect sizes (Cohen's $d$ ) are provided, and Cohen's $d=\left|\frac{\mu_{\text {injured }}-\mu_{\text {sham }}}{s_{\text {pooled }}}\right|$. Effect size $r$ for distance traveled in the EZM on day 21 was calculated as $\left|\frac{z}{\sqrt{N}}\right|$.

$\mathrm{OF}$, open field; EZM, elevated zero maze; MBT, marble burying test.

levels in female mice have been previously observed and discussed. ${ }^{16,31,40,82}$ Also, main effects of sex were noted in the LDB and EZM: females spent less time in the darkened chamber of the LDB than males did, and also engaged in more head-dipping behavior in the EZM. Both of these measures would suggest that the female mice were less anxious than the male mice. There is substantial literature describing sex differences in approach/avoidance tests that goes beyond the scope of this article; however, in recent reviews it was noted that, contrary to human anxiety conditions, female mice and rats more often display fewer anxiety-like behaviors than males in these tests. ${ }^{48,82,83}$ However, conclusions drawn from these tests regarding anxiety again may be difficult when there are differences in activity among groups. ${ }^{75-81}$ For example, factor analysis of EPM behavior in rats has shown that male rats are driven primarily by anxiety, whereas activity is the primary factor in females ${ }^{84}$ and this result has also been demonstrated in OF and EPM behavior in C57BL/6J mice using principal components analysis. ${ }^{85}$ The primary conclusion that can be drawn from these studies is that it is not entirely clear that the classic tests for anxiety commonly employed in TBI pre-clinical work are measuring the same aspect of behavior in male and female rodents, or that results are not complicated by comorbid symptoms resulting from TBI, such as increases or decreases in general levels of arousal and activity.

\section{$\mathrm{CCl}$ and sex affect ethological behaviors in the EZM}

A suggested strategy for overcoming potential locomotor confounds in anxiety tests such as the EZM is to incorporate a more detailed "behavioral ethogram" that includes measures such as SAPs and HDs, believed to be indicative of risk assessment and possibly related to the "apprehension and excessive vigilance" observed in clinical anxiety. ${ }^{75}$ In rodents, a decrease in SAPs and an increase in HDs are indicative of lower levels of anxiety in the EPM or EZM, as benzodiazepines decrease and increase those values, respectively. ${ }^{52}$

The numbers of HDs and U turns, but not SAPs, in this study were affected by injury status. Further, these measures were sensitive to both mild and severe levels of injury, and females made more HDs in the EZM than males did. The effect of injury was dependent upon testing day: mice with severe CCI made fewer head dips than sham controls on the first exposure to the test (Day 2); however, injured mice, independent of severity, made more HDs than sham controls on Day 21. These results suggest that injured mice were more anxious on Day 2 (despite spending less time in the darkened quadrants), but less anxious on Day 21. In addition to the lower number of HDs, injured mice made fewer U turns on the 2nd day following injury, and together, these results might suggest that mice with TBI were engaging in more continuous movements than controls, and that the reduced number of HDs may be a result of a lack of pausing in movement to assess the environment rather than an increase in anxiety. It has been suggested that head dipping may be considered a form of "directed exploration" rather than risk assessment, and may be affected by overall levels of arousal in rodents. ${ }^{78}$ In support of this suggestion, the female mice were more active than the male mice in this test as measured by distance traveled, and they also made more HDs than male mice.

Siopi and colleagues found that male Swiss mice made more HDs in the EPM 3.5 weeks following a weight-drop injury, consistent with our data. ${ }^{68}$ They also found that the number of $U$ turns in the EZM was increased 7 weeks following the injury, although the amount of time in the open quadrants was not affected by injury. ${ }^{68}$ The current data show that mice with both mild and severe brain injury made fewer $U$ turns in the EZM on the 2nd day following $\mathrm{CCI}$, inconsistent with the observations by Siopi and colleagues, the only other TBI translational study to provide this measure. However, there are multiple differences between these two studies, including strain of mice, injury model, and time elapsed between injury and behavioral testing. Regardless, the results from our study suggest that $\mathrm{U}$ turns or ethological behaviors such as HDs may be measures that are more sensitive to milder brain injuries.

\section{Brain-injured mice bury fewer marbles}

The $\mathrm{MBT}^{86}$ is also described as an unconditional test of anxiety. Rats will approach, sniff, and bury marbles as readily as they will 
bury quinine-coated food or the spout of a water bottle filled with tabasco sauce. ${ }^{87}$ Although this test is considered to reflect "defensive burying," there is considerable evidence that mice do not find the marbles aversive, ${ }^{88,89}$ and that marble burying is a byproduct of species-typical digging behavior. For example, the number of marbles buried does not correlate with locomotor activity or measures of anxiety from other paradigms such as the LDB, but does parallel the overall magnitude of digging behavior. ${ }^{88}$ Mice will spend as much time digging in a cage without marbles as it will in a cage with them, ${ }^{88}$ and as digging is a speciesspecific repetitive behavior, the MBT has been suggested as an animal model of obsessive-compulsive disorder (OCD), with greater numbers of marbles buried being indicative of greater anxiety and obsessive/compulsive tendencies. ${ }^{90,91}$

More recently, burrowing has been described as a test of "wellbeing" in mice, reflecting a normal species-typical behavior. This may be more relevant in translational TBI studies, where animals in a painful or diseased state engage in less burrowing, and presumably, bury fewer marbles. ${ }^{92}$ Following repetitive concussive brain injuries, mice buried fewer marbles, ${ }^{61}$ consistent with our study. However, in rats, an impact-accelerated injury delivered by weight drop increased the number of marbles buried. ${ }^{93}$ This discrepancy between these studies may reflect the suggestion that marbles provoke anxiety in rats that TBI may exacerbate, whereas in mice, a brain injury may reduce species-typical digging or burrowing, and, therefore, reduce the number of buried marbles as a result. Regardless of the face validity of the test (for OCD or other forms of clinical anxiety) and translational relevance to anxiety in a clinical TBI population, digging behavior of mice is reduced by hippocampal lesions, ${ }^{94}$ and, as such, may serve as a functional end-point for experimental brain injuries resulting in hippocampal pathology.

\section{Depressive-like behaviors were not affected by TBI or sex}

Two of the core features of depression, anhedonia and behavioral despair, can be measured in rodents with the SPT and FST, respectively. ${ }^{95}$ The FST presents an acute stressor, placement in an inescapable cylinder of water, and measures immobility of rodents which is suggested to be indicative of giving up, or "despair." The SPT evaluates a rodents' preference for a sweetened solution over water; the preference is reduced after a treatment of chronic mild stress. ${ }^{96,97}$ In this study, brain injury delivered to the parietal cortex did not result in depressive symptoms as measured by both the SPT and the FST. To date, anhedonia has been measured in mice following TBI in one study: 2 weeks following two concussive brain injuries, C57BL/6J mice showed a reduced preference for sucrose. ${ }^{98}$ These findings (including the current data) are disparate with regard to injury model, and more studies are warranted to draw conclusions regarding anhedonia in rodent models of experimental TBI.

Compared with the SPT, there have been more studies in mice measuring behavioral despair in the FST and the tail suspension test (TST), a similar test to the FST in which a mouse is hung by the tail and the amount of immobility is used as a measure of behavioral despair. Immobility in these tests is typically scored by an observer, and it is critical that the observer be blinded to the experimental condition of the animals. In our literature review of TBI studies employing these tests, we found that of the studies that did not state that scoring was performed blindly, $91 \%$ of the articles reported TBI-induced behavioral despair, and in this discussion these studies are not considered further. In studies with blinded scoring (in- cluding this one), the incidence of depressive-like behaviors was $43 \%$. In one of the blinded studies reporting behavioral despair, the FST test was conducted the day immediately following 4 days of Morris water maze testing. As the injured animals had cognitive deficits and spent a greater amount of time in the water during those 4 days, behavior in the FST may have been substantially altered by that prior testing experience. Consistent with our results, Wang and colleagues found no effect of parietal CCI on immobility in the FST 28 days following the injury. The most convincing and encouraging results for modeling injury-induced behavioral despair come from studies of concussive brain injuries in which the injury resulted in greater immobility times in the TST. ${ }^{74,98}$ A recent direct comparison of moderate CCI and repeated mild concussive injury in mice suggested that depressive-like behaviors may be more apparent when employing a concussive rather than contusive model of injury, and that the TST may be more sensitive than the FST for measuring despair-like states. ${ }^{38}$

Despite some clinical evidence that females may be more vulnerable to a mood disorder as the result of a brain injury, ${ }^{4,23,24}$ there have been no studies describing sex differences in TBI-induced depressive-like behaviors in rodents. Our data suggest that neither male nor female mice have anhedonia- or despair-like symptoms following parietal CCI. Also, male and female sham controls displayed equivalent levels of immobility and sucrose consumption in the FST and SPT, respectively. A recent review by Kokras and Dalla discusses the complexities of the literature and inconsistencies in results describing differences in behavior between male and female rodents on tests measuring behavioral symptoms of depression. ${ }^{82}$ Although females are twice as likely as males to be diagnosed with depression, ${ }^{18}$ these authors indicate that no clear conclusion can be drawn regarding differences between male and female rat behavior in the FST. However, it has been noted that the majority of studies suggest that male rodents are more susceptible than females to stress and depression-like states, and that it is unknown at what point in evolutionary history sex differences in mood disorders emerged. ${ }^{99}$ With the behavioral tests for depression currently in the pre-clinical toolbox, rodents may simply not be adequate models for the study of sex differences in rodent models of depression, or, more specifically, in modeling gender differences in the susceptibility to mood disorders post-TBI.

\section{Limitations of current experiment}

One of the initial goals of this study was to perform the EZM and LDB at two different time points following TBI to determine if the detection of anxiety-like behaviors was dependent upon the time between the injury and behavioral testing. However, there were differences noted between days 2 and 21 of testing in the sham controls. These differences may reflect test-retest changes, ${ }^{100,101}$ or the effect of single housing. Single housing has been demonstrated to reduce anxiety in the EPM, but increase anxiety in the LDB, ${ }^{102}$ which is partly consistent with our data. Regardless, as novelty is an important component of these tests, if multiple time points are to be sampled, the use of different groups of animals for each time point post-injury is the preferred (however less practical) experimental design for pre-clinical assessments.

A second potentially perceived limitation is that we did not control the hormonal environment or monitor the estrous cycle of the female mice. In the clinical population, females sustain brain injury at all stages of the cycle, so we employed randomly cycling female mice to better resemble the human condition. The other consideration was practical; as many of the tests employed to assess 
function are conducted over many days, it would be very difficult to test and relate estrous cycle stage to each day of behavioral testing. Rats with spinal cord injuries experience disruption in the estrous cycle that may last up to 8 days. ${ }^{103,104}$ It is unknown whether TBI disrupts the estrous cycle or for how long, suggesting continuous monitoring during functional testing would be required, and relating the cycle and resulting hormonal levels to performance in multi-day tests would be very difficult.

The injury model, unilateral parietal CCI, was chosen for this study as it is one of the most frequent brain injuries reported in the literature. The popularity of this model is likely due to its reliability in inducing substantial deficits in motor and cognitive performance. This robust behavioral phenotype provides opportunity for testing potential therapeutic agents for their effectiveness in improving functional outcome. However, this model may not be appropriate for effecting neuropsychiatric symptoms, which may be more apparent after an injury that disrupts alternative circuits or brain regions, such as the medial prefrontal cortex. ${ }^{71}$ There are numerous existing rodent models of TBI that fall into categories such as contusive, concussive, impact acceleration, blast, or a combination of many of these, and these models are not necessarily equal in terms of neuropathological and functional consequences.

\section{Conclusion}

Anxiety and depression are among the most common long-term symptoms in the TBI clinical population. As discussed here and elsewhere, ${ }^{9,70}$ the results from rodent models that feature behavioral assessments of psychiatric disorders after TBI have a significant level of irreconcilability. We have demonstrated that conclusions regarding anxiety following CCI can be disparate based on the assay employed. In the OF, the mice showed increased thigmotaxis indicative of anxiety which has clear clinical relevance, whereas in the EZM and LDB, more specific tests of anxiety, the injured mice spent more time in the anxiogenic zones. "Impulsivity" is a term that has been ascribed to these behaviors in rodents; clinically, however, impulsivity is a broader term that encompasses several symptoms, the most relevant of which is "sensation seeking." However, clinical studies have demonstrated that TBI patients actually experience reductions in "sensation seeking," 105 making that interpretation of reduced anxiety-like behaviors following TBI less plausible.

The female mice in this study showed reduced anxiety in the EZM and LDB, and literature suggests that when activity levels vary among groups (as we found in females and in injured mice), conclusions from anxiety tests should be made with great caution. Monitoring HDs and U turns in the EZM may increase the sensitivity of the test to milder injuries. Injured mice also buried fewer marbles in the hippocampal-dependent MBT, which could be an indication of reduced anxiety, or, a decrease in species-typical behaviors and, therefore, well-being, and this test detected the mild level of injury in the females only. We have also shown that neither injury nor sex affects depressive-like behaviors in the SPT and FST. Finally, we have shown that variability in the behavioral data collected from females at random/unknown stages of the estrous cycle is not higher than the variability in data obtained from male mice.

In addition to recognizing anxiety as a construct that is a challenge to measure in rodents, it is unclear if rodent models are inadequate for pre-clinical modeling of mood and anxiety disorders, or if the TBI research community is not employing the correct assays. The FST and TST have been criticized on the grounds that unlike human depression, the tests are based on acute stress and the behavioral responses are modified rapidly by a single dose of antidepressants. ${ }^{106}$ In addition to other behavioral models that are not based on short-term stress (e.g., unpredictable chronic mild stress and social defeat stress, reviewed by O'Leary and Cryan ${ }^{107}$ ), there are numerous biological correlates to depression that can be measured following TBI. Attempts should be made to incorporate a wider variety of tests for anxiety-like symptoms, and include tests that are not confounded by differences in locomotor activity. Additional assays such as stress-induced hyperthermia ${ }^{108,109}$ and the Vogel conflict test ${ }^{110}$ may have utility in TBI studies.

Although pre-clinical research will likely never be able to capture in rodents the full spectrum of psychiatric symptoms that patients experience following brain injury, attempts can be made to measure multiple behavioral symptoms and physiological parameters with strong correlates to depression in the clinic. There is evidence that psychiatric disorders following TBI are preceded by functional difficulties and perceptions of injury-related limitations. ${ }^{6,111}$ As patients with TBI are susceptible to significant psychosocial stress, incorporation of stressors (including social stress) following experimental TBI may result in a more suitable representation of clinical syndromes and provide a better environment for testing therapeutic agents aimed at alleviating these common psychiatric symptoms. In conclusion, a review of the literature indicates that assessments of neuropsychiatric symptoms in preclinical TBI models have been inconsistent and have failed to fully replicate neuropsychiatric symptoms as sequelae to TBI. Care must be taken in making interpretations from studies where one behavioral measure is made of neuropsychiatric traits after TBI. Confounding factors such as activity should be recognized. Neuropsychiatric approaches also should consider the limitations derived from ethological differences between male and female patients and the interpretation of behavior measures in rodent models.

\section{Acknowledgments}

This work was supported by The Center for Neuroscience and Regenerative Medicine, 60855-300600-7.01. The opinions, interpretations, conclusions, and recommendations are those of the authors and are not necessarily endorsed by the United States Army, Department of Defense, the United States government, or the Uniformed Services University of the Health Sciences. The use of trade names does not constitute an official endorsement or approval of the use of such reagents or commercial hardware or software. This document may not be cited for purposes of advertisement. The authors express appreciation for being able to use the laboratory of Dr. Yumin Zhang for tissue sectioning.

\section{Author Disclosure Statement}

No competing financial interests exist.

\section{References}

1. Jorge, R.E., Robinson, R.G., Starkstein, S.E., and Arndt, S.V. (1993). Depression and anxiety following traumatic brain injury. J. Neuropsychiatry Clin. Neurosci. 5, 369-374.

2. Hibbard, M.R., Ashman, T.A., Spielman, L.A., Chun, D., Charatz, H.J., and Melvin, S. (2004). Relationship between depression and psychosocial functioning after traumatic brain injury. Arch. Phys. Med. Rehabil. 85, S43-53.

3. Hibbard, M.R., Uysal, S., Kepler, K., Bogdany, J., and Silver, J. (1998). Axis I psychopathology in individuals with traumatic brain injury. J. Head Trauma Rehabil. 13, 24-39. 
4. Scholten, A.C., Haagsma, J.A., Cnossen, M.C., Olff, M., Van Beeck, E.F., and Polinder, S. (2016). Prevalence and risk factors of anxiety and depressive disorders following traumatic brain injury: a systematic review. J. Neurotrauma. [Epub ahead of print; PMID 26729611.]

5. Koponen, S., Taiminen, T., Portin, R., Himanen, L., Isoniemi, H., Heinonen, H., Hinkka, S., and Tenovuo, O. (2002). Axis I and II psychiatric disorders after traumatic brain injury: a 30-year follow-up study. Am. J. Psychiatry 159, 1315-1321.

6. Pagulayan, K.F., Hoffman, J.M., Temkin, N.R., Machamer, J.E., and Dikmen, S.S. (2008). Functional limitations and depression after traumatic brain injury: examination of the temporal relationship. Arch. Phys. Med. Rehabil. 89, 1887-1892.

7. Fann, J.R., Hart, T., and Schomer, K.G. (2009). Treatment for depression after traumatic brain injury: a systematic review. J. Neurotrauma 26, 2383-2402.

8. Wheaton, P., Mathias, J.L., and Vink, R. (2011). Impact of pharmacological treatments on outcome in adult rodents after traumatic brain injury: a meta-analysis. J. Psychopharmacol. 25, 1581-1599.

9. Malkesman, O., Tucker, L.B., Ozl, J. and McCabe, J.T. (2013). Traumatic brain injury - modeling neuropsychiatric symptoms in rodents. Front. Neurol. 4, 157.

10. Beery, A.K., and Zucker, I. (2011). Sex bias in neuroscience and biomedical research. Neurosci. Biobehav. Rev. 35, 565-572.

11. O'Connor, C.A., Cernak, I., Johnson, F., and Vink, R. (2007). Effects of progesterone on neurologic and morphologic outcome following diffuse traumatic brain injury in rats. Exp. Neurol. 205, 145-153.

12. Roof, R.L., Duvdevani, R., Braswell, L., and Stein, D.G. (1994). Progesterone facilitates cognitive recovery and reduces secondary neuronal loss caused by cortical contusion injury in male rats. Exp. Neurol. 129, 64-69.

13. Wagner, A.K., Willard, L.A., Kline, A.E., Wenger, M.K., Bolinger, B.D., Ren, D., Zafonte, R.D., and Dixon, C.E. (2004). Evaluation of estrous cycle stage and gender on behavioral outcome after experimental traumatic brain injury. Brain Res. 998, 113-121.

14. Wagner, A.K., Kline, A.E., Ren, D., Willard, L.A., Wenger, M.K., Zafonte, R.D., and Dixon, C.E. (2007). Gender associations with chronic methylphenidate treatment and behavioral performance following experimental traumatic brain injury. Behav. Brain Res. 181, 200-209.

15. Xiong, Y., Mahmood, A., Lu, D., Qu, C., Goussev, A., Schallert, T., and Chopp, M. (2007). Role of gender in outcome after traumatic brain injury and therapeutic effect of erythropoietin in mice. Brain Res. 1185, 301-312.

16. Tucker, L.B., Fu, A.H., and McCabe, J.T. (2016). Performance of male and female C57BL/6J mice on motor and cognitive tasks commonly used in pre-clinical traumatic brain injury research. J. Neurotrauma 33, 880-894.

17. Monaco, C.M., Mattiola, V.V., Folweiler, K.A., Tay, J.K., Yelleswarapu, N.K., Curatolo, L.M., Matter, A.M., Cheng, J.P., and Kline, A.E. (2013). Environmental enrichment promotes robust functional and histological benefits in female rats after controlled cortical impact injury. Exp. Neurol. 247, 410-418.

18. Kessler, R.C., McGonagle, K.A., Zhao, S., Nelson, C.B., Hughes, M., Eshleman, S., Wittchen, H.U., and Kendler, K.S. (1994). Lifetime and 12-month prevalence of DSM-III-R psychiatric disorders in the United States. Results from the National Comorbidity Survey. Arch. Gen. Psychiatry 51, 8-19.

19. Roof, R.L., Duvdevani, R., and Stein, D.G. (1993). Gender influences outcome of brain injury: progesterone plays a protective role. Brain Res. 607, 333-336.

20. Maghool, F., Khaksari, M., and Siahposht Khachki, A. (2013). Differences in brain edema and intracranial pressure following traumatic brain injury across the estrous cycle: involvement of female sex steroid hormones. Brain Res. 1497, 61-72.

21. Bruce-Keller, A.J., Dimayuga, F.O., Reed, J.L., Wang, C., Angers, R., Wilson, M.E., Dimayuga, V.M., and Scheff, S.W. (2007). Gender and estrogen manipulation do not affect traumatic brain injury in mice. J. Neurotrauma 24, 203-215.

22. Hall, E.D., Gibson, T.R., and Pavel, K.M. (2005). Lack of a gender difference in post-traumatic neurodegeneration in the mouse controlled cortical impact injury model. J. Neurotrauma 22, 669-679.

23. Bay, E., Sikorskii, A., and Saint-Arnault, D. (2009). Sex differences in depressive symptoms and their correlates after mild-to-moderate traumatic brain injury. J. Neurosci. Nurs. 41, 298-309.
24. Glenn, M.B., O'Neil-Pirozzi, T., Goldstein, R., Burke, D., and Jacob, L. (2001). Depression amongst outpatients with traumatic brain injury. Brain Inj. 15, 811-818.

25. Clayton, J.A., and Collins, F.S. (2014). Policy: NIH to balance sex in cell and animal studies. Nature 509, 282-283.

26. Sorge, R.E., Martin, L.J., Isbester, K.A., Sotocinal, S.G., Rosen, S., Tuttle, A.H., Wieskopf, J.S., Acland, E.L., Dokova, A., Kadoura, B., Leger, P., Mapplebeck, J.C., McPhail, M., Delaney, A., Wigerblad, G., Schumann, A.P., Quinn, T., Frasnelli, J., Svensson, C.I., Sternberg, W.F., and Mogil, J.S. (2014). Olfactory exposure to males, including men, causes stress and related analgesia in rodents. Nat. Methods 11, 629-632.

27. Budinich, C.S., Tucker, L.B., Lowe, D., Rosenberger, J.G., and McCabe, J.T. (2013). Short and long-term motor and behavioral effects of diazoxide and dimethyl sulfoxide administration in the mouse after traumatic brain injury. Pharmacol. Biochem. Behav. $108,66-73$.

28. Collins, T.J. (2007). ImageJ for microscopy. Biotechniques 43, 2530 .

29. Prendergast, B.J., Onishi, K.G., and Zucker, I. (2014). Female mice liberated for inclusion in neuroscience and biomedical research. Neurosci. Biobehav. Rev. 40, 1-5.

30. Ackerly, D.D., and Jasieński, M. (1990). Size-dependent variation of gender in high density stands of the monoecious annual, Ambrosia artemisiifolia (Asteraceae). Oecologia 82, 474-477.

31. Morgan, M.A., and Pfaff, D.W. (2002). Estrogen's effects on activity, anxiety, and fear in two mouse strains. Behav. Brain Res. 132, $85-93$.

32. Viggiano, D. (2008). The hyperactive syndrome: metanalysis of genetic alterations, pharmacological treatments and brain lesions which increase locomotor activity. Behav. Brain Res. 194, 1-14.

33. Kimbler, D.E., Shields, J., Yanasak, N., Vender, J.R., and Dhandapani, K.M. (2012). Activation of $\mathrm{P} 2 \mathrm{X} 7$ promotes cerebral edema and neurological injury after traumatic brain injury in mice. PLoS One 7 , e41229.

34. Yu, F., Wang, Z., Tchantchou, F., Chiu, C.T., Zhang, Y., and Chuang, D.M. (2012). Lithium ameliorates neurodegeneration, suppresses neuroinflammation, and improves behavioral performance in a mouse model of traumatic brain injury. J. Neurotrauma 29, 362 374.

35. Wakade, C., Sukumari-Ramesh, S., Laird, M.D., Dhandapani, K.M., and Vender, J.R. (2010). Delayed reduction in hippocampal postsynaptic density protein-95 expression temporally correlates with cognitive dysfunction following controlled cortical impact in mice. J. Neurosurg. 113, 1195-1201.

36. Hsieh, C.L., Niemi, E.C., Wang, S.H., Lee, C.C., Bingham, D., Zhang, J., Cozen, M.L., Charo, I., Huang, E.J., Liu, J., and Nakamura, M.C. (2014). CCR2 deficiency impairs macrophage infiltration and improves cognitive function after traumatic brain injury. J. Neurotrauma 31, 1677-1688.

37. Amenta, P.S., Jallo, J.I., Tuma, R.F., and Elliott, M.B. (2012). A cannabinoid type 2 receptor agonist attenuates blood-brain barrier damage and neurodegeneration in a murine model of traumatic brain injury. J. Neurosci. Res. 90, 2293-2305.

38. Bajwa, N.M., Halavi, S., Hamer, M., Semple, B.D., NobleHaeusslein, L.J., Baghchechi, M., Hiroto, A., Hartman, R.E., and Obenaus, A. (2016). Mild concussion, but not moderate traumatic brain injury, is associated with long-term depression-like phenotype in mice. PLoS One 11, e0146886.

39. Hall, C.S. (1934). Emotional behavior in the rat. I. Defecation and urination as measures of individual differences in emotionality. $\mathrm{J}$. Comp. Psychol. 18, 385-403.

40. Archer, J. (1975). Rodent sex differences in emotional and related behavior. Behav. Biol. 14, 451-479.

41. Cunha, J.M. and Masur, J. (1978). Evaluation of psychotropic drugs with a modified open field test. Pharmacology 16, 259-267.

42. Lister, R.G. (1990). Ethologically-based animal models of anxiety disorders. Pharmacol. Ther. 46, 321-340.

43. Prut, L. and Belzung, C. (2003). The open field as a paradigm to measure the effects of drugs on anxiety-like behaviors: a review. Eur. J. Pharmacol. 463, 3-33.

44. File, S.E. (2001). Factors controlling measures of anxiety and responses to novelty in the mouse. Behav. Brain Res. 125, 151-157.

45. Thompson, T., Grabowski-Boase, L., and Tarantino, L.M. (2015). Prototypical anxiolytics do not reduce anxiety-like behavior in the 
open field in C57BL/6J mice. Pharmacol. Biochem. Behav. 133, $7-17$.

46. Heredia, L., Torrente, M., Colomina, M.T., and Domingo, J.L. (2014). Assessing anxiety in C57BL/6J mice: a pharmacologica characterization of the open-field and light/dark tests. J. Pharmacol. Toxicol. Methods 69, 108-114.

47. Crawley, J.N. (2007). What's Wrong with My Mouse? 2nd ed. John Wiley \& Sons, Inc: Hoboken, NJ.

48. Donner, N.C., and Lowry, C.A. (2013). Sex differences in anxiety and emotional behavior. Pflugers Arch. 465, 601-626.

49. Cope, E.C., Morris, D.R., Scrimgeour, A.G., and Levenson, C.W. (2012). Use of zinc as a treatment for traumatic brain injury in the rat: effects on cognitive and behavioral outcomes. Neurorehabil. Neural Repair 26, 907-913.

50. Sajja, V.S., Hubbard, W.B., and VandeVord, P.J. (2015). Subacute oxidative stress and glial reactivity in the amygdala are associated with increased anxiety following blast neurotrauma. Shock $44 \mathrm{Suppl}$ $1,71-78$.

51. Park, E., Eisen, R., Kinio, A., and Baker, A.J. (2013). Electrophysiological white matter dysfunction and association with neurobehavioral deficits following low-level primary blast trauma. Neurobiol. Dis. 52, 150-159.

52. Shepherd, J., Grewal, S., Fletcher, A., Bill, D., and Dourish, C. (1994). Behavioural and pharmacological characterisation of the elevated "zero-maze" as an animal model of anxiety. Psychopharmacology (Berl.) 116, 56-64.

53. Braun, A.A., Skelton, M.R., Vorhees, C.V., and Williams, M.T. (2011). Comparison of the elevated plus and elevated zero mazes in treated and untreated male Sprague-Dawley rats: effects of anxiolytic and anxiogenic agents. Pharmacol. Biochem. Behav. 97, 406415.

54. Tchantchou, F., Tucker, L.B., Fu, A.H., Bluett, R.J., McCabe, J.T., Patel, S., and Zhang, Y. (2014). The fatty acid amide hydrolase inhibitor PF-3845 promotes neuronal survival, attenuates inflammation and improves functional recovery in mice with traumatic brain injury. Neuropharmacology 85, 427-439.

55. Schwarzbold, M.L., Rial, D., De Bem, T., Machado, D.G., Cunha, M.P., dos Santos, A.A., dos Santos, D.B., Figueiredo, C.P., Farina M., Goldfeder, E.M., Rodrigues, A.L., Prediger, R.D., and Walz, R. (2010). Effects of traumatic brain injury of different severities on emotional, cognitive, and oxidative stress-related parameters in mice. J. Neurotrauma 27, 1883-1893.

56. Chauhan, N.B., Gatto, R., and Chauhan, M.B. (2010). Neuroanatomical correlation of behavioral deficits in the CCI model of TBI. J. Neurosci. Methods 190, 1-9.

57. Rachmany, L., Tweedie, D., Li, Y., Rubovitch, V., Holloway, H.W., Miller, J., Hoffer, B.J., Greig, N.H., and Pick, C.G. (2013). Exendin4 induced glucagon-like peptide- 1 receptor activation reverses behavioral impairments of mild traumatic brain injury in mice. Age (Dordr) 35, 1621-1636

58. Baratz, R., Rubovitch, V., Frenk, H., and Pick, C.G. (2010). The influence of alcohol on behavioral recovery after mTBI in mice. J. Neurotrauma 27, 555-563.

59. Yang, Z., Wang, P., Morgan, D., Lin, D., Pan, J., Lin, F., Strang, K.H., Selig, T.M., Perez, P.D., Febo, M., Chang, B., Rubenstein, R., and Wang, K.K. (2015). Temporal MRI characterization, neurobiochemical and neurobehavioral changes in a mouse repetitive concussive head injury model. Sci. Rep. 5, 11178.

60. Yin, T.C., Britt, J.K., De Jesús-Cortés, H., Lu, Y., Genova, R.M., Khan, M.Z., Voorhees, J.R., Shao, J., Katzman, A.C., Huntington, P.J., Wassink, C., McDaniel, L., Newell, E.A., Dutca, L.M., Naidoo, J., Cui, H., Bassuk, A.G., Harper, M.M., McKnight, S.L., Ready, J.M., and Pieper, A.A. (2014). P7C3 neuroprotective chemicals block axonal degeneration and preserve function after traumatic brain injury. Cell Rep. 8, 1731-1740.

61. Nichols, J.N., Deshane, A.S., Niedzielko, T.L., Smith, C.D., and Floyd, C.L. (2016). Greater neurobehavioral deficits occur in adult mice after repeated, as compared to single, mild traumatic brain injury (mTBI). Behav. Brain Res. 298, 111-124.

62. Sierra-Mercado, D., McAllister, L.M., Lee, C.C., Milad, M.R., Eskandar, E.N., and Whalen, M.J. (2015). Controlled cortical impact before or after fear conditioning does not affect fear extinction in mice. Brain Res. 1606, 133-141.

63. Ojo, J.O., Greenberg, M.B., Leary, P., Mouzon, B., Bachmeier, C., Mullan, M., Diamond, D.M., and Crawford, F. (2014). Neurobeha- vioral, neuropathological and biochemical profiles in a novel mouse model of co-morbid post-traumatic stress disorder and mild traumatic brain injury. Front. Behav. Neurosci. 8, 213.

64. Cheng, J.S., Craft, R., Yu, G.Q., Ho, K., Wang, X., Mohan, G., Mangnitsky, S., Ponnusamy, R., and Mucke, L. (2014). Tau reduction diminishes spatial learning and memory deficits after mild repetitive traumatic brain injury in mice. PLoS One 9, e115765.

65. Moojen, V.K., Damiani-Neves, M., Bavaresco, D.V., Pescador, B.B., Comim, C.M., Quevedo, J., and Boeck, C.R. (2012). NMDA preconditioning prevents object recognition memory impairment and increases brain viability in mice exposed to traumatic brain injury. Brain Res. 1466, 82-90.

66. Zohar, O., Rubovitch, V., Milman, A., Schreiber, S., and Pick, C.G. (2011). Behavioral consequences of minimal traumatic brain injury in mice. Acta Neurobiol. Exp. (Wars.) 71, 36-45.

67. Ferreira, A.P., Rodrigues, F.S., Della-Pace, I.D., Mota, B.C., Oliveira, S.M., de Campos Velho Gewehr, C., Bobinski, F., de Oliveira, C.V., Brum, J.S., Oliveira, M.S., Furian, A.F., de Barros, C.S., dos Santos, A.R., Ferreira, J., Fighera, M.R., and Royes, L.F. (2014). HOE-140, an antagonist of B2 receptor, protects against memory deficits and brain damage induced by moderate lateral fluid percussion injury in mice. Psychopharmacology (Berl.) 231, 1935-1948.

68. Siopi, E., Llufriu-Daben, G., Fanucchi, F., Plotkine, M., MarchandLeroux, C., and Jafarian-Tehrani, M. (2012). Evaluation of late cognitive impairment and anxiety states following traumatic brain injury in mice: the effect of minocycline. Neurosci. Lett. 511, 110115 .

69. Watanabe, J., Shetty, A.K., Hattiangady, B., Kim, D.-K., Foraker, J.E., Nishida, H., and Prockop, D.J. (2013). Administration of TSG-6 improves memory after traumatic brain injury in mice. Neurobiol. Dis. 59, 86-99.

70. Washington, P.M., Forcelli, P.A., Wilkins, T., Zapple, D.N., Parsadanian, M., and Burns, M.P. (2012). The effect of injury severity on behavior: a phenotypic study of cognitive and emotional deficits after mild, moderate, and severe controlled cortical impact injury in mice. J. Neurotrauma 29, 2283-2296.

71. McAllister, B.B., Spanswick, S.C., Patel, P.P., Barneto, A.A., and Dyck, R.H. (2015). The effects of chronic fluoxetine treatment following injury of medial frontal cortex in mice. Behav. Brain Res. 290, 102-116.

72. Mouzon, B.C., Bachmeier, C., Ferro, A., Ojo, J.O., Crynen, G., Acker, C.M., Davies, P., Mullan, M., Stewart, W., and Crawford, F. (2014). Chronic neuropathological and neurobehavioral changes in a repetitive mild traumatic brain injury model. Ann. Neurol. 75, 241254.

73. Mannix, R., Berglass, J., Berkner, J., Moleus, P., Qiu, J., Andrews, N., Gunner, G., Berglass, L., Jantzie, L.L., Robinson, S., and Meehan, W.P., 3rd (2014). Chronic gliosis and behavioral deficits in mice following repetitive mild traumatic brain injury. J. Neurosurg. 121, 1342-1350.

74. Petraglia, A.L., Plog, B.A., Dayawansa, S., Chen, M., Dashnaw, M.L., Czerniecka, K., Walker, C.T., Viterise, T., Hyrien, O., Iliff, J.J., Deane, R., Nedergaard, M., and Huang, J.H. (2014). The spectrum of neurobehavioral sequelae after repetitive mild traumatic brain injury: a novel mouse model of chronic traumatic encephalopathy. J. Neurotrauma 31, 1211-1224.

75. Cryan, J.F., and Holmes, A. (2005). The ascent of mouse: advances in modelling human depression and anxiety. Nat. Rev. Drug Discov. 4, 775-790.

76. Pires, G.N., Tufik, S., and Andersen, M.L. (2015). Sleep deprivation and anxiety in humans and rodents-translational considerations and hypotheses. Behav. Neurosci. 129, 621-633.

77. Bouwknecht, J.A., and Paylor, R. (2008). Pitfalls in the interpretation of genetic and pharmacological effects on anxiety-like behaviour in rodents. Behav. Pharmacol. 19, 385-402.

78. Weiss, S.M., Wadsworth, G., Fletcher, A., and Dourish, C.T. (1998). Utility of ethological analysis to overcome locomotor confounds in elevated maze models of anxiety. Neurosci. Biobehav. Rev. 23, 265-271.

79. Dawson, G.R., Crawford, S.P., Collinson, N., Iversen, S.D., and Tricklebank, M.D. (1995). Evidence that the anxiolytic-like effects of chlordiazepoxide on the elevated plus maze are confounded by increases in locomotor activity. Psychopharmacology (Berl.) 118, 316-323. 
80. Milner, L.C., and Crabbe, J.C. (2008). Three murine anxiety models: results from multiple inbred strain comparisons. Genes Brain Behav. 7, 496-505.

81. Bourin, M. and Hascoet, M. (2003). The mouse light/dark box test. Eur. J. Pharmacol. 463, 55-65.

82. Kokras, N., and Dalla, C. (2014). Sex differences in animal models of psychiatric disorders. Br. J. Pharmacol. 171, 4595-4619.

83. Palanza, P. (2001). Animal models of anxiety and depression: how are females different? Neurosci. Biobehav. Rev. 25, 219-233.

84. Fernandes, C., Gonzalez, M.I., Wilson, C.A., and File, S.E. (1999). Factor analysis shows that female rat behaviour is characterized primarily by activity, male rats are driven by sex and anxiety. Pharmacol. Biochem. Behav. 64, 731-738.

85. An, X.L., Zou, J.X., Wu, R.Y., Yang, Y., Tai, F.D., Zeng, S.Y., Jia, R., Zhang, X., Liu, E.Q., and Broders, H. (2011). Strain and sex differences in anxiety-like and social behaviors in $\mathrm{C} 57 \mathrm{BL} / 6 \mathrm{~J}$ and BALB/cJ mice. Exp. Anim. 60, 111-123.

86. Broekkamp, C.L., Rijk, H.W., Joly-Gelouin, D., and Lloyd, K.L. (1986). Major tranquillizers can be distinguished from minor tranquillizers on the basis of effects on marble burying and swiminduced grooming in mice. Eur. J. Pharmacol. 126, 223-229.

87. Poling, A., Cleary, J., and Monaghan, M. (1981). Burying by rats in response to aversive and nonaversive stimuli. J. Exp. Anal. Behav. $35,31-44$.

88. Thomas, A., Burant, A., Bui, N., Graham, D., Yuva-Paylor, L.A., and Paylor, R. (2009). Marble burying reflects a repetitive and perseverative behavior more than novelty-induced anxiety. Psychopharmacology (Berl.) 204, 361-373.

89. Gyertyan, I. (1995). Analysis of the marble burying response: marbles serve to measure digging rather than evoke burying. Behav. Pharmacol. 6, 24-31.

90. Deacon, R.M.J. (2006). Digging and marble burying in mice: simple methods for in vivo identification of biological impacts. Nat. Protoc. $1,122-124$.

91. Angoa-Perez, M., Kane, M.J., Briggs, D.I., Francescutti, D.M., and Kuhn, D.M. (2013). Marble burying and nestlet shredding as tests of repetitive, compulsive-like behaviors in mice. J. Vis. Exp., 50978.

92. Jirkof, P. (2014). Burrowing and nest building behavior as indicators of well-being in mice. J. Neurosci. Methods 234, 139-146.

93. Pandey, D.K., Yadav, S.K., Mahesh, R., and Rajkumar, R. (2009). Depression-like and anxiety-like behavioural aftermaths of impact accelerated traumatic brain injury in rats: a model of comorbid depression and anxiety? Behav. Brain Res. 205, 436-442.

94. Deacon, R.M., and Rawlins, J.N. (2005). Hippocampal lesions, species-typical behaviours and anxiety in mice. Behav. Brain Res. 156, 241-249.

95. Slattery, D.A., and Cryan, J.F. (2014). The ups and downs of modelling mood disorders in rodents. ILAR J 55, 297-309.

96. Willner, P., Towell, A., Sampson, D., Sophokleous, S., and Muscat, R. (1987). Reduction of sucrose preference by chronic unpredictable mild stress, and its restoration by a tricyclic antidepressant. Psychopharmacology (Berl.) 93, 358-364.

97. Katz, R.J. (1981). Animal model of depression: effects of electroconvulsive shock therapy. Neurosci. Biobehav. Rev. 5, 273-277.

98. Klemenhagen, K.C., O’Brien, S.P., and Brody, D.L. (2013). Repetitive concussive traumatic brain injury interacts with post-injury foot shock stress to worsen social and depression-like behavior in mice. PLoS One 8, e74510.

99. Cryan, J.F., and Mombereau, C. (2004). In search of a depressed mouse: utility of models for studying depression-related behavior in genetically modified mice. Mol. Psychiatry 9, 326-357.

100. Rodgers, R.J., and Shepherd, J.K. (1993). Influence of prior maze experience on behaviour and response to diazepam in the elevated plus-maze and light/dark tests of anxiety in mice. Psychopharmacology (Berl.) 113, 237-242.

101. Cook, M.N., Crounse, M., and Flaherty, L. (2002). Anxiety in the elevated zero-maze is augmented in mice after repeated daily exposure. Behav. Genet. 32, 113-118.

102. Voikar, V., Polus, A., Vasar, E., and Rauvala, H. (2005). Long-term individual housing in $\mathrm{C} 57 \mathrm{BL} / 6 \mathrm{~J}$ and DBA/2 mice: assessment of behavioral consequences. Genes Brain Behav. 4, 240-252.

103. Hubscher, C.H., Armstrong, J.E., and Johnson, J.R. (2006). Effects of spinal cord injury on the rat estrous cycle. Brain Res. 1100, 118-124.

104. Shah, P.K., Song, J., Kim, S., Zhong, H., Roy, R.R., and Edgerton, V.R. (2011). Rodent estrous cycle response to incomplete spinal cord injury, surgical interventions, and locomotor training. Behav. Neurosci. 125, 996-1002.

105. Rochat, L., Beni, C., Billieux, J., Azouvi, P., Annoni, J.M., and Van der Linden, M. (2010). Assessment of impulsivity after moderate to severe traumatic brain injury. Neuropsychol. Rehabil. 20, 778-797.

106. Nestler, E.J., and Hyman, S.E. (2010). Animal models of neuropsychiatric disorders. Nat. Neurosci. 13, 1161-1169.

107. O'Leary, O.F., and Cryan, J.F. (2013). Towards translational rodent models of depression. Cell Tissue Res. 354, 141-153.

108. Adriaan Bouwknecht, J., Olivier, B., and Paylor, R.E. (2007). The stress-induced hyperthermia paradigm as a physiological animal model for anxiety: a review of pharmacological and genetic studies in the mouse. Neurosci. Biobehav. Rev. 31, 41-59.

109. Olivier, B., Zethof, T., Pattij, T., van Boogaert, M., van Oorschot, R., Leahy, C., Oosting, R., Bouwknecht, A., Veening, J., van der Gugten, J., and Groenink, L. (2003). Stress-induced hyperthermia and anxiety: pharmacological validation. Eur. J. Pharmacol. 463, 117-132.

110. Millan, M.J. and Brocco, M. (2003). The Vogel conflict test: procedural aspects, $\gamma$-aminobutyric acid, glutamate and monoamines. Eur. J. Pharmacol. 463, 67-96.

111. Schonberger, M., Ponsford, J., Gould, K.R., and Johnston, L. (2011). The temporal relationship between depression, anxiety, and functional status after traumatic brain injury: a cross-lagged analysis. J. Int. Neuropsychol. Soc. 17, 781-787.

Address correspondence to: Joseph T. McCabe, PhD

Department of Anatomy, Physiology, and Genetics F.E. Hébert School of Medicine Uniformed Services University of the Health Sciences 4301 Jones Bridge Road Bethesda, MD 20814-4799

E-mail: Joseph.McCabe@usuhs.edu 